\title{
Cultural Determinants of Household Saving Behavior
}

\author{
Nicola Fuchs-Schündeln \\ Goethe University Frankfurt
}

\author{
Paolo Masella \\ University of Bologna
}

February 15, 2017

\author{
Hannah Paule-Paludkiewicz \\ Goethe University Frankfurt *
}

\section{Preliminary and incomplete - please do not cite}

\begin{abstract}
Relying on the epidemiological approach, we show that culture is a significant driver of household saving behavior. Second-generation immigrants from countries that put strong emphasis on thrift or wealth accumulation tend to save more in Germany. We confirm these results in data from the UK. By linking parents to their children, we show that these two cultural components affect the saving behavior of both first-generation immigrants and their children, and also provide suggestive evidence that long-term orientation is related to saving behavior through the intergenerational transmission of language.
\end{abstract}

JEL-Classification: D14, Z10

Keywords: saving, culture, immigrants

\footnotetext{
${ }^{*}$ We thank conference and seminar participants at the European University Institute, Goethe University Frankfurt, University College London, Center for European Economic Research (ZEW), Spring Meeting of Young Economists (Lisbon), the International German Socio-Economic Panel User Conference and the Annual Meeting of the German Economic Association for helpful comments. We also thank Friedrich Scheller for sharing Stata code.
} 


\section{Introduction}

Culture significantly influences household behavior. A vast literature finds that cultural components matter for decisions concerning female labor supply (e.g. Fernández, 2007; Alesina and Giuliano, 2010; Blau, 2015), male employment (Moriconi and Peri, 2015), fertility (Fernández and Fogli, 2009), family living arrangements (e.g. Giuliano, 2007; Furtado et al., 2013) and household portfolio composition (Haliassos et al., 2015). Evidence on the link between culture and household saving behavior is, however, still scarce and inconclusive, possibly due to data limitations. Carroll et al. (1994) and Carroll et al. (1999) do not find evidence that differences in saving rates between cultural groups can be attributed to cultural factors. Recent works, however, seem to suggest a more prominent role of beliefs and preferences (in particular related to future orientation attitudes) in shaping household saving choices, namely via the channel of language (see Chen, 2013).

We revisit the question whether culture affects household saving behavior by relying on household data that provide measures of the propensity to save and information about the cultural origin of household members and their ancestors, and by resorting to several world-wide surveys containing rich arrays of attitudinal variables that can be used to more precisely isolate what cultural components explain variation across households in saving rates. We follow Guiso et al. (2006) and define culture as "those customary beliefs and values that ethnic, religious, and social groups transmit fairly unchanged from generation to generation".

We adopt the so-called epidemiological approach in order to identify the effect of culture on savings (Fernández, 2008). The epidemiological approach links the behavior of second-generation migrants, who all face common economic and institutional factors in the host country, to attitudes and behavior of individuals in the home country of their ancestors. If culture is persistent, second-generation immigrants should still possess values and beliefs of their parents' home country culture. Differences in the saving behavior of second-generation immigrants of different countries of ancestry that correlates with cultural attitudes in their country of ancestry are hence an indicator of cultural effects. We analyze the saving behavior of second-generation immigrants in Germany, additionally providing supporting evidence from the UK. ${ }^{1}$

The epidemiological literature links attitudes or behavior of second-generation immigrants to either attitudes (e.g. Luttmer and Singhal, 2011) or behavior (e.g. Fernández and Fogli, 2009) of individuals in their country of ancestry. While we present results using both approaches, we believe that the first is more appro-

\footnotetext{
${ }^{1}$ Paule (2012) analyzes the saving behavior of first-generation German immigrants. In contrast, we study second-generation immigrants, whose saving behavior is less likely to be affected by immigration related issues.
} 
priate when studying saving decisions because of data issues concerning the availability and comparability of national saving rates. We thus rely in our main analysis on attitudinal variables from the countries of ancestry.

With reference to the economic-psychological literature (Wärneryd, 1999), we distinguish between five different cultural aspects that may affect saving behavior. These are 1. thrift, 2 . the prevalent desire for effective accumulation and improvement, 3. self-control, 4. attitudes towards the future (long-term versus short-term orientation), and 5. reaction to uncertainty. To measure these different cultural aspects at the home country level, we construct cultural proxy variables based on some of the most widely recognized cultural cross-country data sets, namely the World Values Survey / European Values Study, the Hofstede data set, and the Schwartz Value Survey.

While we focus on Germany in our main analysis, we confirm our results using data from the United Kingdom. For both Germany and the UK, we identify significant effects of culture on savings. The two cultural motives that we persistently find to matter are, first, the desire for accumulation, which we measure by the importance assigned to wealth, material possession, and money; and, secondly, attitudes towards thrift. Both variables, measured at the level of the country of ancestry, have a significant effect on the saving behavior of second-generation migrants. These effects are robust in a series of checks including different sample adjustments, alternative estimation techniques, and the inclusion of additional control variables. Our estimates suggest that moving from the country at the 25 th percentile in the distribution of the attitudes towards thrift to the country at the 75 th percentile increases the saving rate by about 1.3 percentage points, and a similar move in the distribution of the desire for accumulation by 0.9 percentage points.

One major advantage of our study compared to other papers from the epidemiological literature is that based on our panel data we can link second-generation immigrants to their parents and study the saving behavior of both. By exploiting the household survey structure and directly linking parents to their children, we confirm significant effects of attitudes concerning wealth accumulation and thrift on both the saving behavior of parents and their children, and also document some assimilation. Moreover, we find that longterm orientation measured in the home country significantly affects the saving behavior of parents, but only the saving behavior of second-generation migrants who speak the parental language well. This finding is in line with the hypothesis by Chen (2013) that future-orientation is induced by the future-time reference of the mother tongue. Finally, we find no robust relationship between saving behavior and self-control or attitudes towards uncertainty, respectively, from the home country for neither second-generation migrants 
nor their parents. This indicates that either the measures we are using to measure self-control and attitude towards uncertainty are inappropriate to capture these cultural aspects, or there exist no cultural effects of these channels on saving behavior, while the attitudes might still matter on the individual level.

This paper contributes to the growing literature that assesses the importance of culture for various economic outcomes, and in particular to studies that analyze the effect of culture on household saving behavior. Using Canadian household data, Carroll et al. (1994) provide a first exploration of the relationship between culture and the propensity to save of households. While they find that the saving behavior of immigrants differs significantly from the saving behavior of natives, they do not find significant differences in the saving behavior of immigrants coming from different cultural origins. However, as they acknowledge in their conclusion, data limitations might be at the root of their findings, since cultural groups are defined in terms of very broad regions of origin (they identify first-generation immigrants from four areas, namely NorthWest Europe, South-East Europe, South-East Asia, and Other Asia). In a subsequent paper, Carroll et al. (1999) use household data from the 1980 and 1990 Census of Population and Housing in the United States. These repeated cross-section data sets contain more detailed information on the country of origin of firstgeneration immigrants, but less precise information on the propensity to save, which must be constructed using estimated changes in household wealth holdings for certain demographic groups over time. They find that saving patterns of immigrants are significantly different across countries of origin, but unrelated to the saving rates in their country of origin. As mentioned above, our panel data set provides detailed information about the saving choices of each household, as well as on the country of origin of the ancestors of each household member. Moreover, we rely on attitudes from the country of ancestry to measure culture, but also show results relying on national saving rates. ${ }^{2}$

Our paper relates as well to the literature analyzing determinants of preferences and beliefs that are likely to be strong predictors of individual saving behavior. In a recent paper, Galor and Özak (2016) trace variation in long-term orientation across countries back to pre-industrial agro-climatic characteristics and, therefore, to historical variation in returns to agricultural investment. Chen (2013) instead relates future

\footnotetext{
${ }^{2}$ Haliassos et al. (2015) and Guiso et al. (2004) suggest that portfolio allocation is influenced by cultural factors. Guiso et al. (2004) provide evidence that the use of financial instruments is affected by the level of social capital of a community. Using Italian data, they show that social capital significantly affects financial development and that communities with higher social capital are more likely to use checks, have higher access to institutional credit (and rely less on informal credit), and invest a larger share of their financial wealth in stocks. Haliassos et al. (2015) consider the relationship between culture and stock ownership, household debt, and home ownership. Studying the behavior of first-generation immigrants, they find significant differences in the financial behavior of immigrants from different cultural groups; however, they do not strive to reconcile the observed financial decisions of immigrants with the financial choices of households in the home country. In line with Haliassos et al. (2015), Huber and Schmidt (2016) identify cultural effects on home ownership.
} 
orientation attitudes of individuals to the grammatical structure of the language spoken by them. Languages that disassociate future from the present make the future more distant and therefore provide less incentives to save. In line with the hypothesis that language structures reflect cultural differences in long-term orientation and that the act of speaking a language of a certain structure matters, we find that the association between the saving behavior of second-generation migrants and the average level of long-term orientation in their country of ancestry is limited to the sample of households who speak the parental language well. ${ }^{3}$ Cronqvist and Siegel (2015) use data on fraternal and identical twins in Sweden, decompose variation in individual savings in environmental and genetic factors, and find evidence that genetic predisposition can explain approximately one third of variation in saving behavior across individuals.

The rest of the paper is structured in the following way. Section 2 describes our identification strategy and Section 3 discusses the data. In Section 4 we present our baseline results and substantiate their robustness. Section 5 provides direct evidence on intergenerational transmission and analyzes the role of language. We complement our analysis with estimates from an alternative country, the UK, in Section 6, and conclude in Section 7.

\section{Empirical Strategy}

In order to disentangle the effect of culture from economic and institutional factors, we study the saving behavior of second-generation immigrants in a single country - Germany in our main analysis. As all immigrants live in the same country, they share the same institutional and economic setting. However, given that culture is persistent over time, there should still be systematic differences in terms of culture among second-generation immigrants if parents transmit values and beliefs to their children. Thus, if we observe differences in the saving behavior of second-generation immigrants from different countries of origin that correlate with attitudes in the home country, we argue that these should be attributable to cultural differences. ${ }^{4}$

Analyzing the behavior of second-generation immigrants is beneficial as compared to first-generation immigrants, because second-generation migrants are less likely to migrate back to the home country of their

\footnotetext{
${ }^{3}$ Figlio et al. (2016) find that students from countries with higher future orientation display better educational outcomes (higher test scores, higher grades in math and reading tests, and higher likelihood of graduating from high school).

${ }^{4}$ When studying labor market outcomes, one might be worried that discrimination based on country of origin may be correlated with the relevant cultural explanatory variables. Differential discrimination is however less likely a concern when we consider saving outcomes, since access to saving accounts is unlikely to be restricted because of discriminatory motives, and one could even save without an account.
} 
parents (one third of second-generation immigrants in our sample do not even speak the language of the home country well), and residual concerns that results are driven by institutional factors in the countries of origin are thus attenuated. Moreover, Fernández (2008) argues that studying second-generation immigrants mitigates biases due to differential selection into immigration by country of origin. Immigrants are obviously a selected sample. Any common selection of individuals closer to the German culture into migration simply biases the results against finding a cultural effect. In addition, gradual assimilation to the culture of the host country is likely more pronounced for second-generation immigrants than for first-generation immigrants, which again biases the relevant coefficient on the cultural variable towards zero. However, differential selection could generate a positive bias if in countries with a cultural environment more favorable to savings the pool of individuals who migrate away is characterized by higher levels of saving rates. Under the assumption that saving rates of parents and children are not correlated through other links than cultural ones, selective migration should not be a concern for second-generation immigrants anymore. Of course, this might be a strong assumption, since saving rates of parents and children could be correlated e.g. due to low intergenerational income mobility, or due to intra-family risk sharing motives. However, we want to point out that in the final sample we have individuals from 69 different countries, making it not very likely that a spurious correlation between the cultural environment related to saving in the home country and the selection of migrants with respect to their saving inclination exists.

Using survey data from several sources, we define a variety of cultural proxies, e.g. the average attitudes towards thrift, and then associate the value of each cultural proxy in the country of origin of the ancestors of the household head to each household in the sample. Because the saving rate, our dependent variable, is censored from below, we rely on a Tobit model. In our main sample, the saving rate is zero for $45 \%$ of the observations. We pool the observations of all survey waves and specify the following model:

$$
s_{h c t}=\max \left(0, \alpha_{0}+\beta C_{c}+Z_{h c t} \gamma+D_{t} \theta+\varepsilon_{h c t}\right) .
$$

$s_{h t c}$ is the saving rate of household $h$ from country of ancestry $c$ in period $t . C_{c}$ is the cultural proxy variable that varies at the home country level, and thus $\beta$ is the main coefficient of interest. If there are cultural effects on saving behavior, we expect $\beta$ to be significant, with the sign depending on the specific cultural trait measured by $C_{c}$. $Z_{h c t}$ is a vector of time-varying household level control variables. $D_{t}$ represents a vector of year dummies for the different survey waves. We cluster the standard errors at the country of 
origin level.

\section{Data}

\subsection{Individual Data}

We use data from the German Socio-Economic Panel (GSOEP), a representative annual panel study that interviews more than 11,000 households in Germany since 1984. ${ }^{5}$ As households report their savings in 1992 for the first time, we use data from 1992 to 2014. A major advantage of the GSOEP is that it oversamples immigrants, which allows us to study the saving behavior of a large number of immigrants from all over the world.

The survey question on savings reads as follows: "Do you usually have an amount of money left over at the end of the month that you can save for larger purchases, emergency expenses or to build up savings? If yes, how much?" To compute the saving rate, we divide the average monthly amount of household savings by the average monthly household net income. Given that savings are reported at the household level, we only keep household heads. ${ }^{6}$

We conduct our analysis based on a sample of second-generation immigrants. We define secondgeneration immigrants as individuals who are born in Germany and either have or had a foreign nationality, or at least one parent immigrated to Germany. Thus, the sample could also contain a few third- or highergeneration immigrants who keep the foreign nationality. In the literature, the home country of ancestry of second-generation immigrants is usually identified based on the birth country of the parents. The GSOEP data set does not directly provide this information. Therefore, to identify the home country, we consider information on current and past citizenships of the second-generation immigrants and also information on the parental citizenships, following the procedure proposed by Scheller (2011). ${ }^{7}$ Whenever information is conflicting, the key rule is to assign the country that was named most often. A detailed description of the procedure is given in Section A.1. Note that the data set from the UK which we use in Section 6 allows us to precisely identify second-generation immigrants as individuals whose parents migrated to the UK, as well as their country of origin. However, it contains a lower number of countries of origin.

We restrict our sample to household heads who are not in school anymore, older than 25 , and younger

\footnotetext{
${ }^{5}$ See Wagner et al. (2008) for more details on the GSOEP data set.

${ }^{6} \mathrm{We}$ drop one observation because its saving rate is larger than 100 .

${ }^{7}$ We only made slight adjustments to the STATA code that was kindly provided to us by Scheller.
} 
than 65. Our sample consists of 6,534 observations (1,391 households) from 69 countries. We impose a minimum household income of 350 Euros, which is approximately equal to the minimum welfare payment for a single individual in Germany. Based on the GSOEP data we construct the following set of individual controls. In the most restrictive specification, we include as exogenous controls only age group dummies comprising 5 ages, and gender. In the baseline specification, we add a list of potentially endogenous controls, starting with decile dummies for the real monthly net household income, and decile dummies for a measure of permanent income, which we construct by averaging the real monthly net income of a household over all available years. ${ }^{8}$ We control for the number of adults in the household, and the number of children younger than 16 living in the household. For children, we construct three dummy variables for "one kid", "two kids", and "three or more kids"; "no kids" is the base category. To control for the marital status we introduce dummies for being married, divorced, and widowed, with single as the excluded category. For education, we use the ISCED classification. "Inadequate education" is the omitted category, and we control for "general elementary", "middle vocational", "vocational or abitur", "higher vocational", and "higher education". We control for the labor market status using dummies for being unemployed, not in the labor force, retired, self-employed, or a civil servant, with being employed being the base category. Finally, we add dummies for the state of residence, relying on the 16 German states. Summary statistics of all relevant variables in the GSOEP are presented in Table 1.

Table 2 summarizes the countries of origin and the respective number of observations in our sample. While the majority of individuals are from European countries, we also observe second-generation immigrants from several different Asian, African, and North and South American countries. The largest groups of immigrants stem from the so-called former "guest worker"9 countries Turkey and Italy, followed by the Czech Republic and the former Yugoslavia.

\subsection{Cultural Data}

As pointed out in the introduction, we use in our main analysis country level measures of attitudes that potentially matter for saving behavior as cultural explanatory variables, and in an alternative specification national saving rates.

\footnotetext{
${ }^{8}$ A similar measure of permanent income has e.g. been used by Bauer and Sinning (2011), who average the monthly net household income over the last five years.

${ }^{9}$ The term "guest worker" refers to migrant workers who moved to Germany especially during the 1960s and 1970s in the context of bilateral recruitment agreements between Germany and countries like Turkey, Italy, Greece, Spain, Morocco, Portugal, Tunisia, South Korea and Yugoslavia.
} 
Table 1: Summary Statistics

\begin{tabular}{|c|c|c|c|c|}
\hline Household characteristics & Mean & Standard deviation & Min & Max \\
\hline Saving rate (in \%) & 7.71 & 10.78 & 0.00 & 83.31 \\
\hline Age & 38.47 & 10.80 & 25.00 & 65.00 \\
\hline No. of kids $($ age $<16)$ & 0.83 & 1.01 & 0.00 & 7.00 \\
\hline No. of adults & 1.83 & 0.65 & 1.00 & 7.00 \\
\hline Female & 0.47 & & 0.00 & 1.00 \\
\hline Single & 0.31 & & 0.00 & 1.00 \\
\hline Married & 0.56 & & 0.00 & 1.00 \\
\hline Divorced & 0.11 & & 0.00 & 1.00 \\
\hline Widowed & 0.02 & & 0.00 & 1.00 \\
\hline Real net monthly income (in 2010 EUR) & 2571 & 1458 & 353 & 18000 \\
\hline Real net monthly permanent income (in 2010 EUR) & 2573 & 1281 & 378 & 17474 \\
\hline Education: inadequate & 0.03 & & 0.00 & 1.00 \\
\hline Education: general elementary & 0.17 & & 0.00 & 1.00 \\
\hline Education: middle vocational & 0.44 & & 0.00 & 1.00 \\
\hline Education: vocational or abitur & 0.07 & & 0.00 & 1.00 \\
\hline Education: higher vocational & 0.08 & & 0.00 & 1.00 \\
\hline Education: higher edcation & 0.22 & & 0.00 & 1.00 \\
\hline Employed & 0.60 & & 0.00 & 1.00 \\
\hline Self-employed & 0.05 & & 0.00 & 1.00 \\
\hline Retired & 0.06 & & 0.00 & 1.00 \\
\hline Not in labor force & 0.17 & & 0.00 & 1.00 \\
\hline Unemployed & 0.08 & & 0.00 & 1.00 \\
\hline Civil service & 0.04 & & 0.00 & 1.00 \\
\hline
\end{tabular}

Based on GSOEP data from the years 1992-2014. The sample consists of second-generation migrants who are household heads, aged 25 to 65, not in school, with a household net income of at least 350 Euros and a saving rate smaller or equal to $100 \%$. 
Table 2: Composition of the GSOEP Sample

\begin{tabular}{|c|c|c|c|}
\hline Europe (5066) & Asia (1276) & Americas (99) & Africa (93) \\
\hline $\begin{array}{l}\text { Austria (310) } \\
\text { Belarus (4) } \\
\text { Belgium (89) } \\
\text { Bosnia-Herzegovina (40) } \\
\text { Bulgaria (3) } \\
\text { Croatia (146) } \\
\text { Czech Republic (585) } \\
\text { Denmark (22) } \\
\text { Estonia (5) } \\
\text { Former Yugoslavia (504) } \\
\text { Finland (13) } \\
\text { France (117) } \\
\text { Greece (490) } \\
\text { Hungary (208) } \\
\text { Italy (967) } \\
\text { Kosovo (6) } \\
\text { Latvia (6) } \\
\text { Lithuania (11) } \\
\text { Luxembourg (9) } \\
\text { Macedonia (38) } \\
\text { Monetenegro (4) } \\
\text { Netherlands (211) } \\
\text { Norway (4) } \\
\text { Poland (481) } \\
\text { Portugal (20) } \\
\text { Romania (129) } \\
\text { Serbia (52) } \\
\text { Slovakia (74) } \\
\text { Slovenia (25) } \\
\text { Spain (309) } \\
\text { Sweden (12) } \\
\text { Switzerland (39) } \\
\text { UK (94) } \\
\text { Ukraine (39) }\end{array}$ & $\begin{array}{l}\text { Bangladesh (1) } \\
\text { India (4) } \\
\text { Indonesia (2) } \\
\text { Iran (4) } \\
\text { Jordan (31) } \\
\text { Kazakhastan (11) } \\
\text { Korea (13) } \\
\text { Kyrgyzstan (1) } \\
\text { Lebanon (12) } \\
\text { Pakistan (1) } \\
\text { Philippines (10) } \\
\text { Russia (120) } \\
\text { Syria (6) } \\
\text { Tadzhikistan (3) } \\
\text { Turkey (1052) } \\
\text { Vietnam (5) }\end{array}$ & $\begin{array}{l}\text { Bolivia (2) } \\
\text { Brazil (3) } \\
\text { Canada (20) } \\
\text { Chile (1) } \\
\text { Costa Rica (12) } \\
\text { Cuba (2) } \\
\text { Ecuador (1) } \\
\text { Guatemala (5) } \\
\text { Paraguay (13) } \\
\text { Peru (2) } \\
\text { USA (38) }\end{array}$ & $\begin{array}{l}\text { Algeria (2) } \\
\text { Cape Verde (2) } \\
\text { Ghana (18) } \\
\text { Morocco (17) } \\
\text { Namibia (29) } \\
\text { Nigeria (2) } \\
\text { Togo (2) } \\
\text { Tunisia (21) }\end{array}$ \\
\hline
\end{tabular}

The number of observations is indicated in brackets. If a country belongs to more than one continent, it is classified according to the largest geographical area. 
Cultural channels To determine which cultural aspects could potentially matter for the saving behavior of households, we resort to the economic-psychological literature. In his book "The Psychology of Saving", Wärneryd (1999) reviews the economic and psychological literature with the aim of identifying factors that determine saving behavior. He identifies six such factors: 1 . thrift / thrifty habits , 2. the prevalent desire for effective accumulation and improvement, 3. self-control / willpower, 4. time horizon / attitude towards the future, 5. uncertainty of the future / role of expectations, and 6. selective perception / limited cognitive capacity.

Wärneryd (1999) emphasizes that the first factor "thrift / thrifty habits" is often assumed to be the most important psychological aspect for saving and that the "inculcation" of this factor is more widespread in some countries than in others. As for the second channel, Wärneryd (1999) points out that in general "people prefer more to less of something attractive", but that there may be moral principles that restrict this desire. Thus, if the accumulation of wealth is more wildly accepted in some cultures than in others, this may have an impact on the saving behavior. Third, differences in "self-control / willpower" may lead to differences in saving behavior. The fourth item "time horizon / attitude towards the future" refers to differences in the time preferences of people. These differences may in turn influence the intertemporal behavior of households. As for the fifth item "uncertainty of the future / role of expectations", Wärneryd (1999) points out that individuals have to deal with uncertainty when deciding how much to save for the future. Different ways of coping with uncertainty may lead to differences in saving choices. Finally, while "selective perception / limited cognitive capacity" has been named e.g. by Marshall (1920) to matter for savings, we think of this as a purely individual factor, which does not qualify for cultural analyses. At this point, it is important to stress that this list of psychological factors mostly refers to individual saving motives. It is our task to analyze whether these aspects also carry over to the more aggregate cultural level, and to find adequate measures at the cultural level.

Cultural attitudinal variables To capture the different cultural channels discussed above, we construct proxies based on three of the most widely used attitudinal data sets, namely the World Value Survey / European Values Study (WVS / EVS), the Hofstede data set, and the Schwartz Value Survey (SVS). The World Values Survey (WVS, 2009) and the European Values Study (EVS, 2011) are nationally representative surveys about beliefs and preferences, which have been conducted in nearly 100 countries worldwide. We follow the procedure described by Díez-Medrano (2009) to combine the different waves of the WVS / EVS 
Table 3: Cultural attitudinal variables

\begin{tabular}{lll}
\hline Wärneryd (1999): Cultural Aspect & Cultural Proxy Variable & Data Set \\
& & \\
\hline Thrift / thrifty habits & Attitudes towards teaching children thrift & WVS / EVS \\
Desire for accumulation and improvement & Importance of wealth accumulation & SVS \\
Self-control / willpower & Indulgence vs restraint & Hofstede \\
& Importance of indulgence & SVS \\
Time horizon / attitude towards the future & Long-term vs short-term orientation & Hofstede \\
Uncertainty of the future / role of expectations & Uncertainty avoidance & Hofstede \\
\hline
\end{tabular}

from 1981 to 2009 into one integrated data set.

The second cultural data set that we use is the cultural dimensions data set of Hofstede. The social psychologist Hofstede extracted cultural dimensions from answers to attitudinal survey questions using factor analysis (Hofstede, 1980). Hofstede interviewed IBM employees from 70 countries between 1967 and 1973, and originally constructed four cultural dimensions. Nowadays, the survey has been extended and replicated also based on different groups of respondents (e.g. students), in different countries and by different researchers. The data set that we employ features six cultural dimensions for 78 to 96 countries, depending on the dimension. We make use of three of the cultural dimensions, all scaled from 0 to $100 .{ }^{10}$

Last, we consider data from the Schwartz Value Survey, a data set that was established based on the Schwartz Theory of Basic Values (Schwartz, 1999, 2012) and provides comparable data on values for 71 different countries. It was conducted between 1988 and 2005, and more than 75,000 individuals, largely K-12 school teachers and undergraduate students, participated in the survey (Schwartz, 2005). They had to evaluate the importance of 57 value items as "a guiding principle in my life" on a scale from 7 ("of supreme importance") to -1 ("opposed to my values"). We use the average rating of the respective value items in each country (corrected for differences in scale use) and re-scale the variables to a scale from 0 to 100.

Table 3 provides the list of the cultural aspects named by Wärneryd (1999) and the corresponding proxies. To construct a cultural proxy that measures the importance of thrift across countries, we use a variable from the WVS / EVS. In each wave, participants are asked: "Here is a list of qualities that children can be encouraged to learn at home. Which, if any, do you consider to be especially important? Please choose up

\footnotetext{
${ }^{10}$ See http://www.geert-hofstede.com for the most recent version of the data set.
} 
to five." One of the items on the list is "Thrift: saving money and things", which participants can rank either as "important" or "not important". We compute the fraction of participants in each country that considers thrift to be important and average this value over all existing waves. ${ }^{11}$

To measure the prevalent desire for effective accumulation and improvement, we use a value item from the SVS. Participants are asked to rate the importance of "wealth (material possessions, money)" as a guiding principle in their life. Higher values of this variable (called "wealth accumulation" in the following) indicate a higher importance assigned to wealth accumulation in the respective country.

To study whether self-control / willpower is an important cultural determinant of household saving behavior, we compute two different proxies. First, we use the Hofstede dimension "indulgence versus restraint". As described by Hofstede (2011), this variable is "related to the gratification versus control of basic human desires related to enjoying life". Similar to the indulgence measure by Hofstede, there exists the item "self-indulgent (doing pleasant things)" in the Schwartz Value Survey that we use to construct a second indulgence variable. This helps us to cross-check the results for the Hofstede indulgence measure. Higher values of these two variables indicate higher levels of indulgence.

As a cultural proxy for time horizon / attitude towards the future, we use the Hofstede dimension "longterm versus short-term orientation". While long-term orientation accounts for "the fostering of virtues oriented toward future rewards", short-term orientation stands "for the fostering of virtues related to the past and the present" (Hofstede and Hofstede, 2005). The variable takes on larger values for countries with a stronger long-term orientation. Hofstede constructs the scores of this variable based on data from the World Value Survey, ${ }^{12}$ and the thrift variable mentioned above is one of the input variables used in the factor analysis. We decide to keep both variables as cultural aspects, given that Wärneryd (1999) considers them different aspects, and given that the Hofstede long-term orientation variable is used in different other studies (see e.g. Figlio et al., 2016; Galor and Özak, 2016; Galor et al., 2016). Yet, when interpreting the results, one should keep the overlap between the thrift and the long-term orientation variables in mind. The exact construction of the Hofstede variables is described in Appendix Section A.2.

Finally, to proxy for the cultural channel that was labeled uncertainty of the future / role of expectations by Wärneryd (1999), we use the "uncertainty avoidance" dimension. Hofstede and Hofstede (2005) define it as "the extent to which the members of a culture feel threatened by ambiguous or unknown situations".

\footnotetext{
${ }^{11}$ For Ex-Yugoslavia, we compute the population weighted average.

${ }^{12}$ The dimension was originally developed based on data from the Chinese Value Survey, which resulted in scores for 23 countries. The WVS-based scores are highly correlated with the original ones, but are available for 93 countries.
} 
The higher the index, the more pronounced is avoidance of uncertainty.

Country saving rates as cultural variables National saving rates can reflect both differences in economic conditions and institutions in the respective country of ancestry, as well as differences in cultural attitudes. Since differences in economic conditions and institutions are not relevant anymore for second-generation immigrants in Germany (unless they intend to migrate back to their country of ancestry), they could potentially serve as cultural proxy variables. We thus run specifications with two measures of national saving rates, namely the national saving rate provided by the World Bank in the World Development Indicators, and the OECD household saving rate. The World Bank measure has the advantage of wide availability; it is available for 68 of our countries of ancestry. However, it has the major disadvantage that apart from household saving, it includes also savings by firms and by the government. This undermines their suitability as a cultural proxy in our analysis. ${ }^{13}$

The second measure provided by the OECD has the advantage that it refers to household saving rates, but the disadvantage that it is only available for OECD countries, China, Russia and South Africa, i.e. 26 of our countries of ancestry. Moreover, this measure still faces issues of comparability across countries: it sometimes refers to net and sometimes to gross saving rates, and pensions provided by the government are accounted for in inconsistent ways across countries. ${ }^{1415}$.

\section{Results}

\subsection{Results Based on Attitudinal Variables}

Figure 1 shows the correlation between the different survey based cultural variables described in Section 3.2 averaged at the home country level on the x-axis, and the average household saving rate of the respective second-generation immigrants in Germany on the y-axis. ${ }^{16}$ Panels (a), (b), and (e) of Figure 1 show that second-generation immigrants tend to save more in Germany if thrift, wealth accumulation, and long-term orientation are valued more in the country of origin, which is in line with our cultural hypothesis. If indul-

\footnotetext{
${ }^{13}$ Figure A2 plots the evolution over time of the national saving rates of each of the 68 countries in the sample; time series are sometimes fairly short and volatile.

${ }^{14}$ It also includes savings by non-profit institutions serving households (NPISH), but this is is likely only a very small share of total household saving.

${ }^{15}$ Country time series are plotted in Figure A3. They are on average shorter than for the World Bank saving rate.

${ }^{16}$ We only include countries with more than 15 observations in the figure. The regression analysis includes all available observations.
} 
gence mattered for saving behavior, we would expect a negative relationship: second-generation immigrants from countries with higher preferences for indulgence would be expected to save less. Panel (c) shows a very slight negative correlation between the indulgence measure based on the SVS and saving behavior of second-generation immigrants, which is however much more pronounced if the Hofstede measure for indulgence is used in panel (d). Finally, we would expect a positive correlation between the uncertainty avoidance variable and households' propensity to save. There is however only a very weak positive correlation between our measure of uncertainty avoidance and the saving behavior of second-generation immigrants in Germany shown in panel (e).

Table 4 reports results from a regression analysis as detailed in equation 1 . The table reports unconditional marginal effects of Tobit models and the respective standard errors. Standard errors are clustered at the country of origin level. Each column contains a different cultural variable indicated at the top of the column.

Panel A shows the estimation results without any control variables. The results are in line with our findings in Figure 1. The marginal effects of the thrift and wealth accumulation variables are positive and significantly different from zero. Thus, second-generation immigrants whose parents come from countries of ancestries that value thrift and wealth accumulation exhibit higher saving rates in Germany. In line with Figure 1, the evidence on the cultural attitude of indulgence is mixed. While the marginal effect of the Hofstede indulgence variable is negative and significantly different from zero at the $10 \%$ level, the effect of the Schwartz indulgence variable on household savings is very close to zero. The marginal effects of the long-term orientation proxy and uncertainty avoidance are not significantly different from zero. For long-term orientation, the marginal effect is quite large, but so is the standard error, while for uncertainty avoidance the effect is close to zero. ${ }^{17}$ Controlling for age and gender of the head of the household leaves all results fairly unchanged (see Panel B of Table 4).

Our baseline results with the full set of control variables are reported in Panel C of Table 4. The marginal effects of the thrift and wealth accumulation variables are positive and significant at the $1 \%$ level, though they become smaller once all control variables are added. Given that we run regressions with six different

\footnotetext{
${ }^{17}$ Regarding the long-term orientation proxy, one interpretation would be that long-term orientation is not transmitted as a cultural trait across generations, or does not matter for saving behavior. Remember, however, that the Hofstede variable contains the thrift variable from the WVS/EVS. If one considers thrift as a component of long-term orientation, opposite to what Wärneryd (1999) does, an alternative interpretation of the result would be that the other variables used in the construction of Hofstede's long-term orientation measure are in fact not good proxies of long-term orientation and thus simply introduce measurement error and bias the coefficient towards zero. Against this interpretation speaks however the successful use of Hofstede's variable in many other studies (e.g. Figlio et al., 2016; Galor and Özak, 2016; Galor et al., 2016).
} 
Figure 1: Saving Rates of Second-Generation Immigrants and Cultural Values in Home Country

(a) Thrift

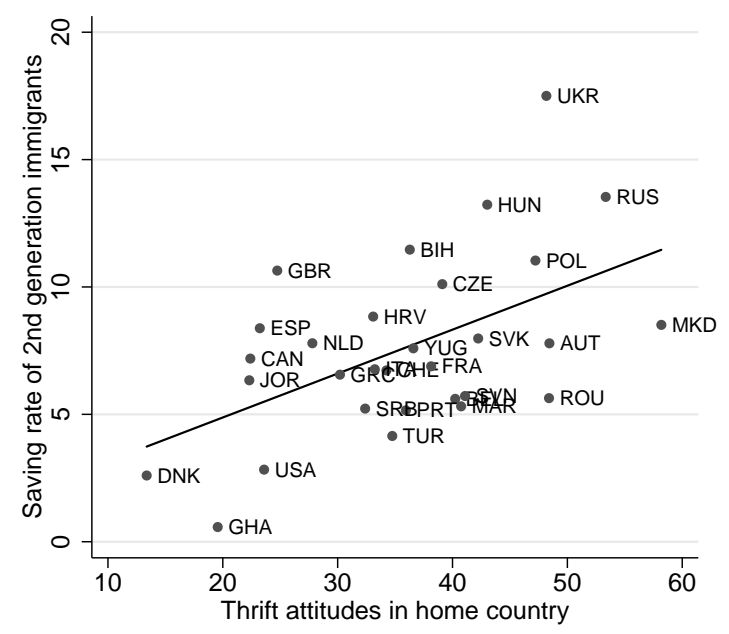

- linear fit

(c) Indulgence (SVS)

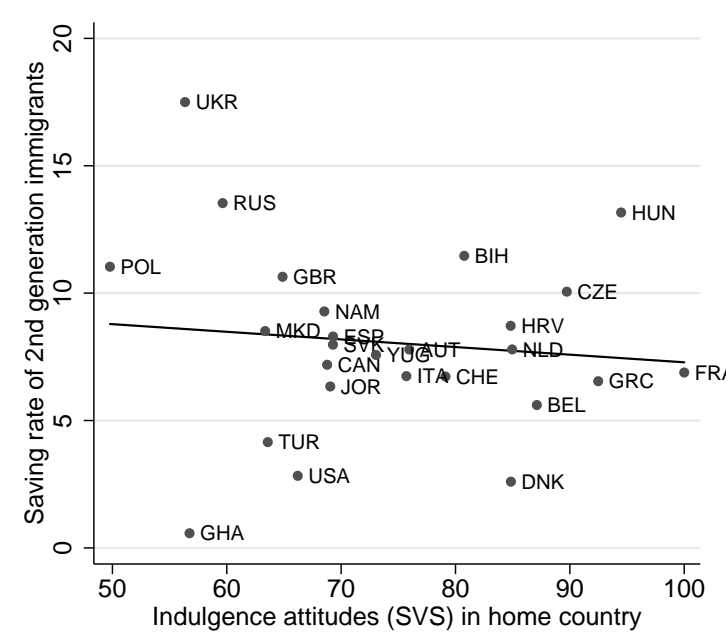

linear fit

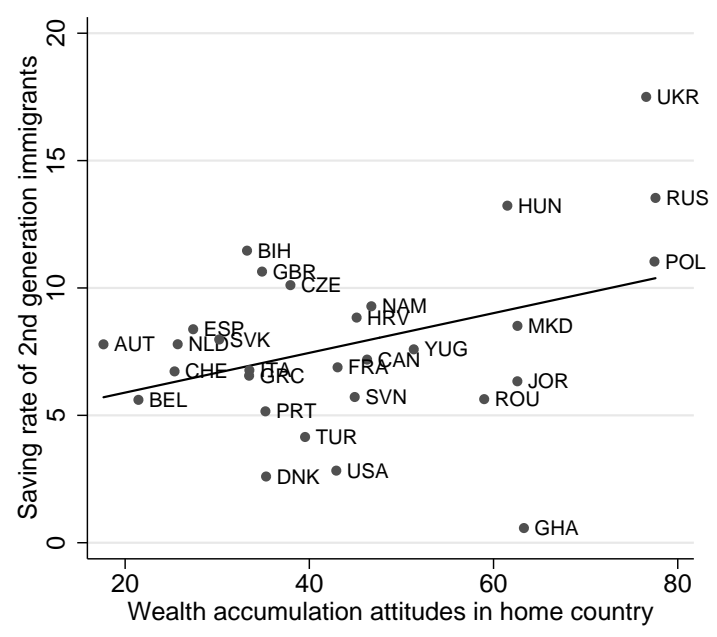

(d) Indulgence (Hofstede)

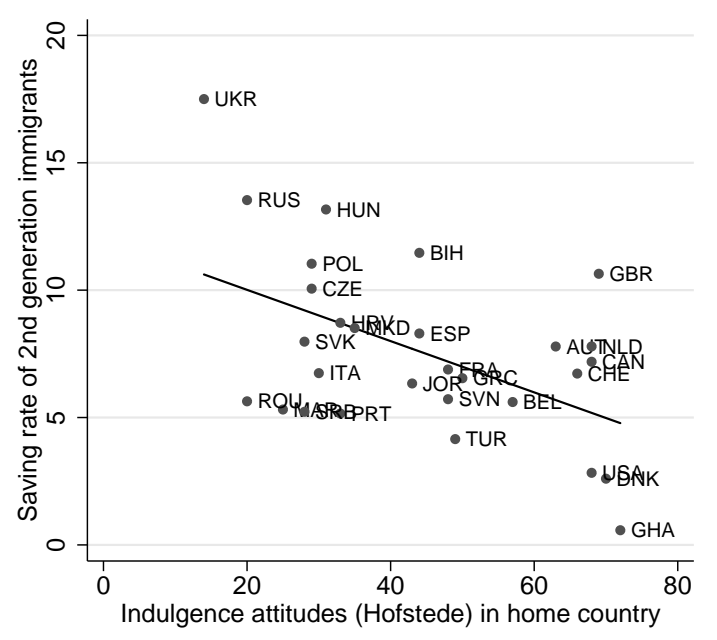

linear fit

(f) Uncertainty Avoidance
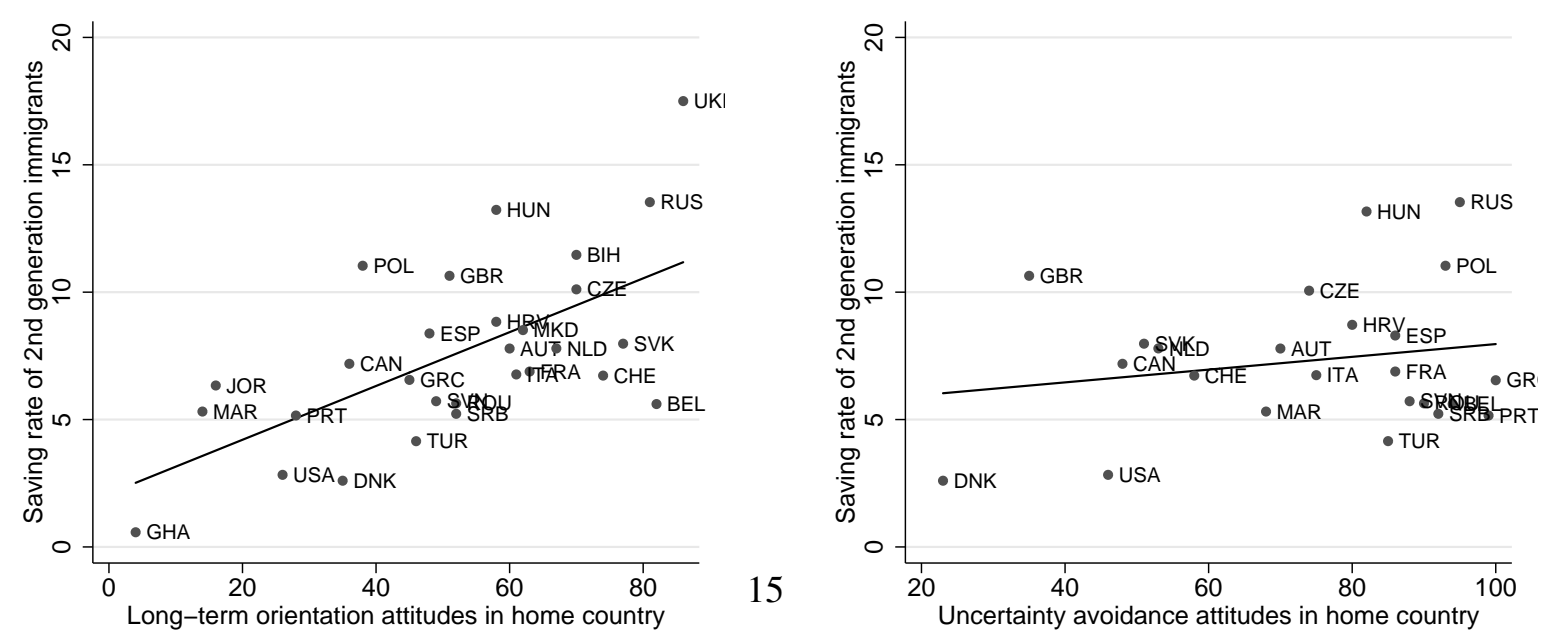

linear fit 
Table 4: Baseline Results

Panel A: without controls

\begin{tabular}{|c|c|c|c|c|c|c|}
\hline Cultural variables & $\begin{array}{c}\text { (1) } \\
\text { Thrift }\end{array}$ & $\begin{array}{c}(2) \\
\text { Wealth } \\
\text { accumulation }\end{array}$ & $\begin{array}{c}(3) \\
\text { Indulgence }\end{array}$ & $\begin{array}{c}(4) \\
\text { Indulgence }\end{array}$ & $\begin{array}{c}\text { (5) } \\
\text { Long-term } \\
\text { orientation }\end{array}$ & $\begin{array}{c}\text { (6) } \\
\text { Uncertainty } \\
\text { avoidance }\end{array}$ \\
\hline Source & WVS / EVS & SVS & SVS & Hofstede & Hofstede & Hofstede \\
\hline $\begin{array}{l}\text { Marginal effect of } \\
\text { cultural variable }\end{array}$ & $\begin{array}{l}0.14 * * \\
(0.06)\end{array}$ & $\begin{array}{c}0.07 * * * \\
(0.02)\end{array}$ & $\begin{array}{c}0.02 \\
(0.06)\end{array}$ & $\begin{array}{l}-0.08^{*} \\
(0.04)\end{array}$ & $\begin{array}{c}0.08 \\
(0.05)\end{array}$ & $\begin{array}{l}-0.02 \\
(0.03)\end{array}$ \\
\hline Observations & 6407 & 6343 & 6140 & 5903 & 5903 & 5742 \\
\hline No. of countries & 54 & 46 & 37 & 53 & 53 & 46 \\
\hline Individual controls & NO & $\mathrm{NO}$ & $\mathrm{NO}$ & $\mathrm{NO}$ & $\mathrm{NO}$ & $\mathrm{NO}$ \\
\hline State dummies & $\mathrm{NO}$ & $\mathrm{NO}$ & $\mathrm{NO}$ & $\mathrm{NO}$ & $\mathrm{NO}$ & $\mathrm{NO}$ \\
\hline Year FE & $\mathrm{NO}$ & $\mathrm{NO}$ & $\mathrm{NO}$ & $\mathrm{NO}$ & $\mathrm{NO}$ & $\mathrm{NO}$ \\
\hline
\end{tabular}

Panel B: controlling for age and gender

\begin{tabular}{|c|c|c|c|c|c|c|}
\hline $\begin{array}{l}\text { Cultural variables } \\
\text { Source }\end{array}$ & $\begin{array}{c}\text { (1) } \\
\text { Thrift } \\
\text { WVS / EVS }\end{array}$ & $\begin{array}{c}(2) \\
\text { Wealth } \\
\text { accumulation } \\
\text { SVS }\end{array}$ & $\begin{array}{c}\text { (3) } \\
\text { Indulgence } \\
\text { SVS }\end{array}$ & $\begin{array}{c}\text { (4) } \\
\text { Indulgence } \\
\text { Hofstede }\end{array}$ & $\begin{array}{c}\quad(5) \\
\text { Long-term } \\
\text { orientation } \\
\text { Hofstede }\end{array}$ & $\begin{array}{c}\text { (6) } \\
\text { Uncertainty } \\
\text { avoidance } \\
\text { Hofstede }\end{array}$ \\
\hline $\begin{array}{l}\text { Marginal effect of } \\
\text { cultural variable }\end{array}$ & $\begin{array}{l}0.12 * * \\
(0.05)\end{array}$ & $\begin{array}{c}0.06 * * * \\
(0.02)\end{array}$ & $\begin{array}{c}0.00 \\
(0.05)\end{array}$ & $\begin{array}{l}-0.06 * \\
(0.03)\end{array}$ & $\begin{array}{c}0.06 \\
(0.05)\end{array}$ & $\begin{array}{l}-0.01 \\
(0.03)\end{array}$ \\
\hline Observations & 6407 & 6343 & 6140 & 5903 & 5903 & 5742 \\
\hline No. of countries & 54 & 46 & 37 & 53 & 53 & 46 \\
\hline Individual controls & SOME & SOME & SOME & SOME & SOME & SOME \\
\hline State dummies & NO & NO & NO & NO & NO & NO \\
\hline Year FE & YES & YES & YES & YES & YES & YES \\
\hline
\end{tabular}

Panel C: with all baseline controls

(1)

Cultural variables Thrift
(2)
(3)
(4)
(5)

\begin{tabular}{lcccccc} 
Source & WVS / EVS & $\begin{array}{c}\text { accumulation } \\
\text { SVS }\end{array}$ & SVS & Hofstede & $\begin{array}{c}\text { orientation } \\
\text { Hofstede }\end{array}$ & $\begin{array}{c}\text { Hoidance } \\
\text { Hofstede }\end{array}$ \\
\hline $\begin{array}{l}\text { Marginal effect of } \\
\text { cultural variable }\end{array}$ & $0.07 * * *$ & $0.04^{* * *}$ & -0.02 & $-0.03 *$ & 0.02 & 0.01 \\
& $(0.02)$ & $(0.01)$ & $(0.02)$ & $(0.02)$ & $(0.02)$ & $(0.02)$ \\
Observations & 6407 & 6343 & 6140 & 5903 & 5903 & 5742 \\
No. of countries & 54 & 46 & 37 & 53 & 53 & 46 \\
Individual controls & YES & YES & YES & YES & YES & YES \\
State dummies & YES & YES & YES & YES & YES & YES \\
Year FE & YES & YES & YES & YES & YES & YES \\
\hline
\end{tabular}

Significance levels: $* * * \mathrm{p}<0.01, * * \mathrm{p}<0.05, * \mathrm{p}<0.1$. The dependent variable is the household saving rate. We estimate Tobit models and present marginal effects. Clustered standard errors (at country of origin level) are reported in parentheses. Individual controls in Panel B are age-group dummies for 5 ages and a gender dummy. Panel C adds as individual controls income decile dummies, permanent income decile dummies; labor market status: dummies for unemployed, not in labor force, retired, self employed, civil servant; marital status: dummies for married, divorced, widowed; five education dummies (ISCED categories); 3 kids dummies: 1 kid, 2 kids, 3 or more kids; and a numerical control variable for the number of adults in the household. 
cultural variables, one might be worried about spurious results in multiple hypothesis testing. To account for this, we also employ the Bonferroni correction, and the results are robust: the marginal effects of thrift and wealth accumulation remain statistically significant at the $1 \%$ level. ${ }^{18} \mathrm{~A}$ one standard deviation increase in the thrift motive corresponds to an increase in the saving rate of 0.84 percentage points. Increasing the wealth accumulation motive by one standard deviation leads to an increase in the saving rate of 0.62 percentage points. ${ }^{19}$ Given a mean saving rate of $7.71 \%$, these correspond to increases in the mean saving rate of $11 \%$ and $8 \%$, respectively.

While the marginal effects of both indulgence variables are negative as expected if all control variables are added, only the Hofstede measure is significantly different from zero at the $10 \%$ level, and turns insignificant under the Bonferroni correction. We also do not find evidence of a robust association between the proxies for long-term orientation and uncertainty avoidance and the saving rate. Once all control variables are added, the coefficient on long-term orientation stays positive, but becomes close to zero.

Thus, based on the results in Table 4, we find evidence for two of the five cultural channels that we consider. Second-generation migrants from countries of ancestry that value thrift and wealth accumulation exhibit significantly higher saving rates in Germany, while the average levels of indulgence, long-term orientation, and uncertainty avoidance in the country of ancestry are not correlated with saving rates of second-generation migrants in Germany. In Section 5, we investigate potential reasons why the last three channels are not supported by the empirical results. One potential explanation may be that these factors just do not matter for the saving behavior of households. A second possibility is that the cultural proxies are simply bad measures of the cultural aspect that we would like to pick. Finally, these factors might matter for the saving behavior of households; however, they might not be transmitted from parents to children across generations. Before we turn to these investigations, we analyze the robustness of the main results, and present results using national saving rates as cultural variables.

\subsection{Robustness}

So far, we found significant cultural effects on saving rates via thrift and the wealth accumulation motive. In this section, we test the robustness of these results with respect to sample adjustments, alternative esti-

\footnotetext{
${ }^{18}$ To guarantee a family-wise error rate of at most level $\alpha$, we individually test the statistical significance of the 6 cultural variables at a significance level of $\alpha / 6$. The $\mathrm{p}$-value of thrift is 0.00086 , the $\mathrm{p}$-value of wealth accumulation is 0.00011 . Thus, using $\alpha=0.01$, the p-values of thrift and wealth accumulation are still smaller than $0.01 / 6=0.0016$.

${ }^{19}$ The standard deviation of the thrift variable is 12.04 , and of the wealth accumulation motive 17.32
} 
Table 5: Robustness Checks

(1)

(2)

Specification

Thrift

Wealth accumulation

\section{Sample adjustments}

Drop smallest countries $(<10$ observations)

Drop largest country (Turkey)

$0.075^{* * *}$

$0.036 * * *$

$(0.022)$

$(0.010)$

Drop largest country (Turkey)

$0.071 * * *$

$0.039 * * *$

European countries only

(0.022)

$(0.011)$

European countries only

$0.079 * * *$

$0.044 * * *$

Drop if cultural proxy highest (top 5\%)

(0.026)

$(0.011)$

Drop if cultural proxy lowest (bottom 5\%)

$0.067 * * *$

$0.034 * * *$

$(0.024)$

$(0.010)$

German citizens only

$0.091^{* * *}$

$0.041 * * *$

(0.027)

(0.010)

$0.074 * *$

$0.035^{* * *}$

$(0.030)$

$(0.012)$

Tighter age group (30-60 years)

$0.067 * * *$

$0.032 * * *$

$(0.021)$

(0.011)

\section{Alternative estimation techniques \\ OLS}

$0.074 * * *$

$0.046^{* * *}$

Random effects Tobit

\section{Alternative dependent variables}

Saving rate incl. remittances

$\begin{array}{cc}0.077 * * * & 0.042 * * * \\ (0.027) & (0.012) \\ 0.003 * * & 0.002 * * * \\ (0.001) & (0.001) \\ 0.004 * * & 0.001 \\ (0.002) & (0.001) \\ -0.001 & 0.000 \\ (0.001) & (0.001)\end{array}$

Individual controls

YES

YES

State dummies

YES

YES

Year FE

YES

YES

Significance levels: $* * * \mathrm{p}<0.01,{ }^{* *} \mathrm{p}<0.05,{ }^{*} \mathrm{p}<0.1$. The dependent variable is the household saving rate. We estimate Tobit models (except for the last three robustness checks, in which we estimate Probit models) and present marginal effects. Clustered standard errors (at country of origin level) are reported in parentheses. We report unclustered standard errors for the random effects Tobit model. Individual controls in Panel B are age-group dummies for 5 ages and a gender dummy. Panel C adds as individual controls income decile dummies, permanent income decile dummies; labor market status: dummies for unemployed, not in labor force, retired, self employed, civil servant; marital status: dummies for married, divorced, widowed; five education dummies (ISCED categories); 3 kids dummies: 1 kid, 2 kids, 3 or more kids; and a numerical control variable for the number of adults in the household. In the falsification check we also control for the self-reported current health status. 
mation techniques, alternative dependent variables, and additional control variables. As depicted in Table 2 , the number of observations is far from equally distributed across countries of ancestry. In order to make sure that our results are not driven by specific home countries, Table 5 presents the marginal effects if we exclude either the country with the most observations, namely Turkey, or the smallest countries with less than 10 observations. In addition, we also run a robustness check focusing on European countries of ancestry only, thereby increasing the homogeneity of the countries of ancestry. Last, we once drop the top 5\% of observations with the highest values of the respective cultural proxy, and once the bottom $5 \%$ with the lowest values to show that the results are not driven by outliers. The estimates are largely unaffected in these five different robustness checks.

Next, we consider the subsample of German citizens only. If immigrants only live in Germany temporarily and plan to return to their countries of origin, their behavior may still be affected by the institutional setting in their home countries. While this may in general be less of a concern for second-generation immigrants, having a German citizenship increases the probability of staying in Germany permanently even further. The results are robust to including the subsample of German citizens only. Having a German citizenship could also be a signal for being more open to the German culture in general. However, as shown by the marginal effects for German citizens, the behavior of this group of people is still significantly affected by the home country culture. This indicates that these values are deeply rooted and not easily given up. In a last sample adjustment, we limit the sample to individuals aged 30 to 60 rather than 25 to 65 , in order to focus on individuals in the core labor market age group. Results are unchanged.

We also report results relying on alternative estimation techniques in Table 5. First, we run OLS estimates rather than a Tobit model, and secondly, we estimate a random effects Tobit model. The random effects Tobit model allows us to take the panel structure of our data set into account. However, standard errors are not clustered at the country of origin level in this case. Both OLS and random effects Tobit models yield very similar results to the baseline Tobit model.

The next set of robustness checks concern alternative dependent variables. In addition to accumulating savings in Germany, immigrants may send money abroad to save in their country of origin. This form of saving is especially important for temporary immigrants (Sinning, 2011; Dustmann and Mestres, 2010). In our sample, $4.9 \%$ of all observations report positive remittances with an average amount of 161.7 Euros per month. ${ }^{20}$ To account for these transfers, we adjust our dependent variable and add remittances to the

\footnotetext{
${ }^{20}$ We classify all transfers that immigrants send either to their children, parents, the spouse or relatives living abroad as remit-
} 
average monthly amount of savings and then divide it by the monthly net household income as before. Results are robust to including remittances as savings. We also provide results focusing on the extensive margin of the saving rate by using as alternative dependent variable a dummy equal to one if household savings are positive. Similarly, we run a specification in which the dependent variable is a dummy equal to one if the the household owns a home. This specification thus focuses on real rather than financial savings, again concerning the extensive margin only. In both cases, we run probit regressions. While both the average level of thrift and wealth accumulation in the country of ancestry are correlated significantly with the extensive margin of savings, only the thrift cultural component is significant in the regression using the home ownership dummy as dependent variable.

Finally, we do a falsification check. Potentially, thrift and wealth accumulation could be proxies for other attitudes that may vary at the home country level, for example independence and self-reliance. If this is true, thrift and wealth accumulation should also have explanatory power for other choices of the household, e.g. whether to visit the doctor or not. ${ }^{21}$ As doctor visits are largely covered by the obligatory health insurance in Germany, attitudes towards thrift or the importance assigned to wealth accumulation should not matter for the decision to visit a doctor. We estimate a Probit model, including the standard set of controls and additionally the self-reported current health status, and use the choice of visiting a doctor or not in the last three month as dependent variable. The estimated marginal effect is -0.001 for thrift and 0.000 for wealth accumulation, confirming that these two variables are not simply proxies for other attitudes in the home country but matter specifically for saving decisions.

tances. These questions have been asked at the personal level since 1996 and refer to the respective previous year. We aggregate the numbers at the household level, lag them by one year and divide them by 12 to get the monthly amount.

${ }^{21}$ We adopt this check from Osili and Paulson (2008). 
Table 6: Robustness Checks: Additional Controls

\begin{tabular}{|c|c|c|c|c|c|c|c|c|c|c|}
\hline Marginal effects & $\begin{array}{c}\text { (1) } \\
\text { Thrift }\end{array}$ & $\begin{array}{c}(2) \\
\text { Wealth }\end{array}$ & $\begin{array}{l}\text { (3) } \\
\text { Thrift }\end{array}$ & $\begin{array}{c}(4) \\
\text { Wealth }\end{array}$ & $\begin{array}{c}\text { (5) } \\
\text { Thrift }\end{array}$ & $\begin{array}{c}(6) \\
\text { Wealth }\end{array}$ & $\begin{array}{l}\text { (7) } \\
\text { Thrift }\end{array}$ & $\begin{array}{c}(8) \\
\text { Wealth }\end{array}$ & $\begin{array}{l}\text { (9) } \\
\text { Thrift }\end{array}$ & $\begin{array}{c}(10) \\
\text { Wealth }\end{array}$ \\
\hline Cultural variable & $\begin{array}{c}0.07 * * * \\
(0.02)\end{array}$ & $\begin{array}{c}0.04 * * * \\
(0.01)\end{array}$ & $\begin{array}{c}0.08 * * * \\
(0.02)\end{array}$ & $\begin{array}{c}0.04 * * * \\
(0.01)\end{array}$ & $\begin{array}{c}0.07 * * * \\
(0.02)\end{array}$ & $\begin{array}{c}0.03^{* * * *} \\
(0.01)\end{array}$ & $\begin{array}{c}0.08 * * * \\
(0.02)\end{array}$ & $\begin{array}{c}0.04 * * * \\
(0.01)\end{array}$ & $\begin{array}{c}0.07 * * * \\
(0.02)\end{array}$ & $\begin{array}{c}0.04 * * \\
(0.01)\end{array}$ \\
\hline Log GDP per capita & $\begin{array}{l}-0.12 \\
(0.40)\end{array}$ & $\begin{array}{c}0.15 \\
(0.61)\end{array}$ & & & & & & & $\begin{array}{l}-0.61 \\
(0.52)\end{array}$ & $\begin{array}{l}-0.39 \\
(0.75)\end{array}$ \\
\hline Africa & & & $\begin{array}{l}-1.62 \\
(1.08)\end{array}$ & $\begin{array}{l}-1.10 \\
(1.58)\end{array}$ & & & & & $\begin{array}{c}-2.94 * * \\
(1.41)\end{array}$ & $\begin{array}{l}-1.90 \\
(1.71)\end{array}$ \\
\hline Americas & & & $\begin{array}{c}2.10 \\
(2.10)\end{array}$ & $\begin{array}{c}2.85 \\
(2.87)\end{array}$ & & & & & $\begin{array}{c}2.36 \\
(1.90)\end{array}$ & $\begin{array}{c}3.20 \\
(2.79)\end{array}$ \\
\hline Asia & & & $\begin{array}{c}-0.85 * * * \\
(0.31)\end{array}$ & $\begin{array}{c}-1.01 * * * \\
(0.35)\end{array}$ & & & & & $\begin{array}{c}-1.11^{* *} \\
(0.49)\end{array}$ & $\begin{array}{c}-1.16^{* * *} \\
(0.55)\end{array}$ \\
\hline Health & & & & & $\begin{array}{c}1.06 * * * \\
(0.28)\end{array}$ & $\begin{array}{c}1.00 * * * \\
(0.29)\end{array}$ & & & $1.14 * * *$ & $1.08 * * *$ \\
\hline Income risk & & & & & & & $\begin{array}{c}1.23 \\
(1.05)\end{array}$ & $\begin{array}{c}1.08 \\
(1.04)\end{array}$ & $\begin{array}{c}1.24 \\
(1.04)\end{array}$ & $\begin{array}{c}1.25 \\
(1.03)\end{array}$ \\
\hline Observations & 6407 & 6343 & 6407 & 6343 & 6314 & 6250 & 6138 & 6090 & 6044 & 6000 \\
\hline Individual controls & YES & YES & YES & YES & YES & YES & YES & YES & YES & YES \\
\hline State dummies & YES & YES & YES & YES & YES & YES & YES & YES & YES & YES \\
\hline Year FE & YES & YES & YES & YES & YES & YES & YES & YES & YES & YES \\
\hline
\end{tabular}

Significance levels: $* * * \mathrm{p}<0.01, * * \mathrm{p}<0.05, * \mathrm{p}<0.1$. The dependent variable is the household saving rate. We estimate Tobit models and present marginal effects. Clustered standard errors (at country of origin level) are reported in parentheses. Individual controls in Panel B are age-group dummies for 5 ages and a gender dummy. Panel $\mathrm{C}$ adds as individual controls income decile dummies, permanent income decile dummies; labor market status: dummies for unemployed, not in labor force, retired, self employed, civil servant; marital status: dummies for married, divorced, widowed; five education dummies (ISCED categories); 3

kids dummies: 1 kid, 2 kids, 3 or more kids; and a numerical control variable for the number of adults in the household. 
We now turn our attention to potentially omitted variables both at the country of origin level and at the individual level. Table 5 reports the regression results. First, we control for log GDP per capita in the country of origin, ${ }^{22}$ and the marginal effects of thrift and wealth accumulation are unaffected. In columns (3) and (4) we add continent dummies to the regressions, using Europe as omitted category. One of the key assumptions of our identification strategy is that all second-generation immigrants face the same institutional environment in Germany. This assumption could be violated if immigrants from some countries are discriminated against. If discrimination is based on the continent of origin, this would be captured by the continent dummies. Still, the cultural effects are robust to including continent dummies. Turning to additional control variables on the individual levels, columns (5) and (6) present results including a dummy for the self-reported current health status of the household head. ${ }^{23}$ While households with a better health status save significantly more, the cultural variables are robust. Moreover, income risk may vary among immigrants from different countries of origin. In the next two columns of Table 5 we provide some evidence that this does not drive our results. As a rough measure for income risk, we compute the standard deviation of log net household income over all available years for each household and include it as a control. The marginal effects of thrift and wealth accumulation are hardly affected. Finally, the last two columns of Table 5 includes all additional countrylevel and individual controls at once, and again results are robust.

So far, we presented regression results for thrift and wealth accumulation separately. Since they are positively correlated, one might worry whether both have significant effects if they are included jointly in the regression. Table 7 presents the results. Whereas column (1) shows the marginal effects if thrift and wealth accumulation are included jointly in the same regression, columns (2) and (3) present the reference values if either thrift or wealth accumulation are included separately using the same subsample of observations for which both cultural variables are available. Controlling for thrift and wealth accumulation at the same time leads to a slight decrease in the size of the two marginal effects. However, both effects are still significantly different from zero, indicating that the two cultural proxies really capture two different cultural channels.

\footnotetext{
${ }^{22}$ We use GDP per capita data based on purchasing power parity (PPP) provided by the Worldbank, take the log and average all available years to get a robust measure. We cross-check the results with GDP per capita data from the Penn World Table and results are robust (not reported here).

${ }^{23}$ Survey respondents describe their current health status on a scale from "very good: 1" to "bad: 5". Our dummy variable is equal to one if the health status is either "very good: 1" or "good: 2", and zero otherwise.
} 
Table 7: Disentangling Channels

\begin{tabular}{|c|c|c|c|}
\hline Cultural variables & $\begin{array}{c}(1) \\
\text { Jointly }\end{array}$ & $\begin{array}{c}(2) \\
\text { Separately }\end{array}$ & $\begin{array}{c}\text { (3) } \\
\text { Separately }\end{array}$ \\
\hline Thrift & $\begin{array}{l}0.04 * \\
(0.02)\end{array}$ & $\begin{array}{c}0.07 * * * \\
(0.02)\end{array}$ & \\
\hline Wealth accumulation & $\begin{array}{c}0.03 * * * \\
(0.01)\end{array}$ & & $\begin{array}{c}0.04 * * * \\
(0.01)\end{array}$ \\
\hline Observations & 6300 & 6300 & 6300 \\
\hline Individual controls & YES & YES & YES \\
\hline State dummies & YES & YES & YES \\
\hline Year FE & YES & YES & YES \\
\hline \multicolumn{4}{|c|}{$\begin{array}{l}\text { Significance levels: } * * * \mathrm{p}<0.01, * * \mathrm{p}<0.05, * \mathrm{p}<0.1 \text {. The dependent vari- } \\
\text { able is the household saving rate. We estimate Tobit models and present } \\
\text { marginal effects. Clustered standard errors (at country of origin level) are } \\
\text { reported in parentheses. Individual controls in Panel B are age-group dum- } \\
\text { mies for } 5 \text { ages and a gender dummy. Panel C adds as individual controls } \\
\text { income decile dummies, permanent income decile dummies; labor market } \\
\text { status: dummies for unemployed, not in labor force, retired, self employed, } \\
\text { civil servant; marital status: dummies for married, divorced, widowed; five } \\
\text { education dummies (ISCED categories); } 3 \text { kids dummies: } 1 \text { kid, } 2 \text { kids, } 3 \\
\text { or more kids; and a numerical control variable for the number of adults in } \\
\text { the household. }\end{array}$} \\
\hline
\end{tabular}

\subsection{Country Saving Rates Results}

We now present results obtained using country saving rates measures as main cultural explanatory variable, loosely following the approach by Carroll et al. (1999). As mentioned in the previous section, we extract two different measures of country saving rates from two separate data sources, the World Bank and the OECD. In Table 8, we report results using both measures as dependent variables: columns 1 to 4 report results using the World Bank measure, columns 5 to 8 results using the OECD measure. Columns 1 and 5 do not include any control variables, columns 2 and 6 include the exogenous controls gender, age, and year fixed effects, columns 3 and 7 include the full standard set of control variables, and columns 4 and 8 additionally include the log of per capita GDP as a control. ${ }^{24}$

While the national saving rate variable by the World Bank in the country of ancestry correlates significantly with the household saving rate of second-generation migrants in Germany only in the specification without any controls, the household saving rate variable by the OECD only does so after controlling for

\footnotetext{
${ }^{24}$ Appendix Figure A1 shows scatterplots associating saving rates of second-generation immigrants in Germany with national saving rates in their home country, without and with controlling for log GDP per capita.
} 
Table 8: Country Saving Rate Results

\begin{tabular}{|c|c|c|c|c|c|c|c|c|}
\hline \multirow[b]{2}{*}{$\begin{array}{l}\text { Cultural variable } \\
\text { Source }\end{array}$} & (1) & (2) & (3) & (4) & (5) & (6) & (7) & (8) \\
\hline & \multicolumn{4}{|c|}{$\begin{array}{l}\text { National saving rate } \\
\text { Worldbank }\end{array}$} & \multicolumn{4}{|c|}{$\begin{array}{l}\text { Household saving rate } \\
\text { OECD }\end{array}$} \\
\hline Cultural variable & $\begin{array}{l}0.24 * \\
(0.13)\end{array}$ & $\begin{array}{c}0.15 \\
(0.12)\end{array}$ & $\begin{array}{c}0.00 \\
(0.05)\end{array}$ & $\begin{array}{c}0.06 \\
(0.05)\end{array}$ & $\begin{array}{l}-0.05 \\
(0.18)\end{array}$ & $\begin{array}{l}-0.03 \\
(0.15)\end{array}$ & $\begin{array}{c}0.04 \\
(0.09)\end{array}$ & $\begin{array}{c}0.19 * * * \\
(0.05)\end{array}$ \\
\hline Log GDP per capita & & & & $\begin{array}{c}-0.94 * * \\
(0.40)\end{array}$ & & & & $\begin{array}{c}-3.36 * * * \\
(0.62)\end{array}$ \\
\hline Observations & 6532 & 6532 & 6532 & 6526 & 4273 & 4273 & 4273 & 4273 \\
\hline No. of countries & 68 & 68 & 68 & 67 & 26 & 26 & 26 & 26 \\
\hline Individual controls & NO & SOME & YES & YES & NO & SOME & YES & YES \\
\hline State dummies & NO & NO & YES & YES & NO & NO & YES & YES \\
\hline Year FE & NO & YES & YES & YES & NO & YES & YES & YES \\
\hline
\end{tabular}

Significance levels: $* * * \mathrm{p}<0.01, * * \mathrm{p}<0.05, * \mathrm{p}<0.1$. The dependent variable is the household saving rate. We estimate Tobit models and present marginal effects. Clustered standard errors (at country of origin level) are reported in parentheses. Individual controls in Panel B are age-group dummies for 5 ages and a gender dummy. Panel $\mathrm{C}$ adds as individual controls income decile dummies, permanent income decile dummies; labor market status: dummies for unemployed, not in labor force, retired, self employed, civil servant; marital status: dummies for married, divorced, widowed; five education dummies (ISCED categories); 3 kids dummies: 1 kid, 2 kids, 3 or more kids; and a numerical control variable for the number of adults in the household.

$\log$ GDP per capita in the country of ancestry. Overall, while results on average point in the direction of a positive relationship between saving rates in the country of ancestry and saving rates of second-generation immigrants, they are not robust and do not allow arriving at significant conclusions. As we describe in the previous section, however, both saving rate measures have several important shortcomings that make them less than perfect proxies of cultural attitudes in the home country: the World Bank saving rate has as a major disadvantage that it includes saving by firms and the government, while the OECD saving rate has issues of comparability across countries and is available for a much smaller set of countries. Thus, the attitudinal variables might be better cultural proxies for our analysis.

\section{Evidence on Intergenerational Effects and Language}

\subsection{Results for Parents and Children}

An advantage of the GSOEP data set is that we are able to study the saving behavior of children and their actual parents if they both participate in the survey. This is of course not the case for all second-generation 
Table 9: Results for Parents and Their Children

Panel A: parents

(1)

\begin{tabular}{|c|c|c|c|c|c|c|}
\hline Cultural variables & $\begin{array}{l}(1) \\
\text { Thrift }\end{array}$ & $\begin{array}{c}(2) \\
\text { Wealth } \\
\text { accumulation } \\
\text { SVS }\end{array}$ & $\begin{array}{c}(3) \\
\text { Indulgence }\end{array}$ & $\begin{array}{c}\text { (4) } \\
\text { Indulgence } \\
\text { Hofstede }\end{array}$ & $\begin{array}{c}\text { (5) } \\
\text { Long-term } \\
\text { orientation } \\
\text { Hofstede }\end{array}$ & $\begin{array}{c}\text { (6) } \\
\text { Uncertainty } \\
\text { avoidance } \\
\text { Hofstede }\end{array}$ \\
\hline $\begin{array}{l}\text { Marginal effect of } \\
\text { cultural variable }\end{array}$ & $\begin{array}{c}0.16^{* * * *} \\
(0.04)\end{array}$ & $\begin{array}{c}0.07 * * * \\
(0.02)\end{array}$ & $\begin{array}{c}0.02 \\
(0.02)\end{array}$ & $\begin{array}{l}-0.01 \\
(0.02)\end{array}$ & $\begin{array}{c}0.08^{* * *} \\
(0.02)\end{array}$ & $\begin{array}{l}-0.04 * \\
(0.02)\end{array}$ \\
\hline Observations & 2447 & 2410 & 2353 & 1957 & 1957 & 1956 \\
\hline Individual controls & YES & YES & YES & YES & YES & YES \\
\hline State dummies & YES & YES & YES & YES & YES & YES \\
\hline Year FE & YES & YES & YES & YES & YES & YES \\
\hline \multicolumn{7}{|l|}{ Panel B: children } \\
\hline Cultural variables & $\begin{array}{l}\text { (1) } \\
\text { Thrift }\end{array}$ & $\begin{array}{c}(2) \\
\text { Wealth } \\
\text { accumulation }\end{array}$ & $\begin{array}{c}\text { (3) } \\
\text { Indulgence }\end{array}$ & $\begin{array}{c}\text { (4) } \\
\text { Indulgence }\end{array}$ & $\begin{array}{c}\text { (5) } \\
\text { Long-term } \\
\text { orientation }\end{array}$ & $\begin{array}{c}\text { (6) } \\
\text { Uncertainty } \\
\text { avoidance }\end{array}$ \\
\hline Source & WVS / EVS & SVS & SVS & Hofstede & Hofstede & Hofstede \\
\hline $\begin{array}{l}\text { Marginal effect of } \\
\text { cultural variable }\end{array}$ & $\begin{array}{l}0.08^{*} \\
(0.04)\end{array}$ & $\begin{array}{c}0.03 \\
(0.03)\end{array}$ & $\begin{array}{l}-0.01 \\
(0.03)\end{array}$ & $\begin{array}{l}-0.02 \\
(0.03)\end{array}$ & $\begin{array}{c}0.04 \\
(0.04)\end{array}$ & $\begin{array}{l}-0.02 \\
(0.03)\end{array}$ \\
\hline Observations & 2812 & 2804 & 2716 & 2381 & 2381 & 2321 \\
\hline Individual controls & YES & YES & YES & YES & YES & YES \\
\hline State dummies & YES & YES & YES & YES & YES & YES \\
\hline Year FE & YES & YES & YES & YES & YES & YES \\
\hline
\end{tabular}

Significance levels: $* * * \mathrm{p}<0.01, * * \mathrm{p}<0.05, * \mathrm{p}<0.1$. The dependent variable is the household saving rate. We estimate Tobit models and present marginal effects. Clustered standard errors (at country of origin level) are reported in parentheses. Individual controls in Panel B are age-group dummies for 5 ages and a gender dummy. Panel $\mathrm{C}$ adds as individual controls income decile dummies, permanent income decile dummies; labor market status: dummies for unemployed, not in labor force, retired, self employed, civil servant; marital status: dummies for married, divorced, widowed; five education dummies (ISCED categories); 3 kids dummies: 1 kid, 2 kids, 3 or more kids; and a numerical control variable for the number of adults in the household. We do not impose any age restriction here. The sample of parents consists of parents that self-report that they intend to stay in Germany permanently. 
immigrants, but for a non-negligible part of our sample, given the panel structure of GSOEP which follows children that leave the household to form their own. An analysis of this kind is typically not possible in studies relying on the epidemiological approach. Linking parents to their children allows us to analyze whether the impact of home country culture is present in the sample of first-generation immigrants, and whether it is persistent across generations.

Table 9 presents the marginal effects of our standard regressions for parents (first-generation immigrants) in Panel A, and the effects for their actual children (second-generation immigrants) in Panel B. ${ }^{25}$ We only include parents in the sample who report the intention to stay in Germany permanently and whose incentives to save should thus not be driven by institutional details in their home country. All regressions include the full set of control variables specified before. We find positive and significant effects of the attitudes towards thrift and of wealth accumulation in the home country on the saving behavior of parents. This confirms our baseline results that these two cultural channels affect the saving behavior of households. Although we cannot measure the transmission process of attitudes directly, the fact that we find positive effects of these attitudes on the saving behavior of both parents and children can be interpreted as preliminary evidence for the transmission of saving preferences from parents to children, consistent with previous findings by Knowles and Postlewaite (2004). Comparing the size of the marginal effects for the two main cultural variables, we find that the effect is approximately two times larger for the parents than for the children, suggesting some assimilation over time. Note that the marginal effect on the wealth accumulation motive becomes insignificant for children in the smaller sample here, while it is significant in the full sample of second-generation migrants.

In Section 4.1 we discuss three possible explanations for the absence of a significant relationship between measures of indulgence, long-term orientation, and uncertainty avoidance in the country of ancestry and second-generation immigrants' saving decisions, namely that 1 . these attitudes are not determinants of saving decisions, 2. there are measurement problems of the attitudes, or 3. cultural values are not transmitted across generations. Here, we can further differentiate between these possible explanations. The marginal effects for the indulgence measures in the home country are insignificant for both parents and children. This indicates that either indulgence is not a cultural trait that matters for saving behavior, or that the two indulgence measures that we use are both inappropriate to measure the underlying trait. For uncertainty

\footnotetext{
${ }^{25}$ While we restrict our sample to those between age 25 and 65 in the rest of the paper, we drop this restriction here to maximize the number of parent-children pairs observed.
} 
avoidance, we get similar results, though the coefficient is marginally significant at $10 \%$ in the parental sample, but with the wrong sign. Thus, for both indulgence and uncertainty avoidance, we can rule out the third explanation above that the attitudes vary on the national level and effects of these attitudes on saving behavior are present, but are not transmitted from parents to children. Unfortunately, we are not able to distinguish further between the remaining two potential reasons. Finally, considering long-term orientation, we find a positive and significant marginal effect in the sample of parents, but a smaller and insignificant effect in the sample of children. The coefficient of 0.04 in the children's sample is however still larger than the coefficient in the baseline results for all second-generation migrants, where it amounts to 0.02. Thus, the evidence points towards long-term orientation in the home country having an effect for first-generation immigrants, but no significant effect for second generation. Thus, it seems that this cultural trait might not be transmitted across generations. We investigate this further in the next section.

Note that all these results are largely robust to either including parents who self-report the intention to return to their country of ancestry in the sample of parents, or to including remittances to the measures of savings, or both. These results can be found in Appendix Section A.5.

\subsection{Language and Culture}

In this section, we analyze a potential explanation for the finding that long-term orientation in the home country has a significant effect on the saving behavior of first-generation migrants, but not of their children. Chen (2013) and Sutter et al. (2015) argue that it is the spoken language that induces either long-term or short-term orientation. They show that speakers of languages with obligatory distinction between the present and the future (for example English) behave less future oriented, e.g. save less. In contrast, speakers of languages that grammatically do not clearly separate the future and the present (for example German) perceive the future to be closer and are thus more likely to save. Consistent with the results by Chen (2013), Guin (2015) finds differences in the saving behavior of individuals from different language groups within Switzerland. Yet, it is hard to disentangle whether long-term orientation is directly transmitted as a cultural trait and languages simply reflect culture, or whether the act of speaking a language matters, or both channels are present to some degree.

First-generation immigrants are much more likely to speak the language of their home country. If it is the act of speaking the language itself that leads to the cultural transmission of time preferences, this could explain why long-term orientation matters for the saving behavior of first-generation immigrants, but 
Table 10: Language and Long-Term Orientation

\begin{tabular}{lcc}
\hline & $\begin{array}{c}\text { Marginal effects } \\
\text { of cultural variable }\end{array}$ & $N$ \\
\hline Specification & & \\
\hline Cultural variable: long-term orientation (Hofstede) & $0.06^{*}$ & 1561 \\
Subsample: high language proficiency & $(0.03)$ & \\
& 0.02 & 2016 \\
Subsample: low language proficiency & $(0.02)$ & \\
& & \\
Cultural variable: thrift (WVS/EVS) & 0.07 & 1673 \\
Subsample: high language proficiency & $(0.05)$ & 2284 \\
& 0.06 & \\
Subsample: low language proficiency & $(0.04)$ & \\
& & \\
Cultural variable: wealth accumulation (SVS) & 0.01 & 1651 \\
Subsample: high language proficiency & $(0.03)$ & \\
& 0.03 & 2237 \\
Subsample: low language proficiency & $(0.02)$ & \\
\hline
\end{tabular}

Significance levels: $* * * \mathrm{p}<0.01, * * \mathrm{p}<0.05, * \mathrm{p}<0.1$. The dependent variable is the household saving rate. We estimate Tobit models and present marginal effects. Clustered standard errors (at country of origin level) are reported in parentheses. Individual controls in Panel B are age-group dummies for 5 ages and a gender dummy. Panel $\mathrm{C}$ adds as individual controls income decile dummies, permanent income decile dummies; labor market status: dummies for unemployed, not in labor force, retired, self employed, civil servant; marital status: dummies for married, divorced, widowed; five education dummies (ISCED categories); 3 kids dummies: 1 kid, 2 kids, 3 or more kids; and a numerical control variable for the number of adults in the household. 
not for second-generation immigrants. To investigate this hypothesis, we use a variable from the GSOEP that indicates how well immigrants speak the language of their parents. This variable is based on a selfassessment of language proficiency on a 5 point-scale from 1 (speak the language very well) to 5 (do not speak the language at all) and is only available in six waves. As language proficiency is likely to change only relatively slowly over time, we compute the mean value over time for every person and assign this value to the individual for all available survey years. In a second step, we split the sample of second-generation immigrants based on their language proficiency. One subsample consists of second-generation immigrants who indicate to speak the parental language either "well" or "very well". Second-generation immigrants that are less proficient in their parent's language are grouped into the second subsample. According to the hypothesis by Chen (2013) that the act of speaking a language with more or less future-time reference matters for inducing long-term orientation, the long-term orientation variable should affect savings only for the subgroup of people that are able to speak the language of their parents well. Note that the home languages of the second-generation migrant sample do not contain enough variation according to Chen's measure of future-orientation in order to exploit variation in both whether a second-generation migrant speaks the parental home language and in the structure of this language. ${ }^{26}$ Our analysis thus relies on the identifying assumption that variation in long-term orientation across cultures indeed expresses itself in some features of the spoken languages that we do not directly identify. It could indeed be the case that long-term orientation expresses itself in other grammatical or linguistic features than the ones pointed out by Chen (2013). Under this maintained assumption, we can shed some light on the question whether languages simply reflect long-term orientation but are not directly responsible for its cultural transmission, or whether the act of speaking a language itself matters for affecting long-term orientation, i.e. on the direction of causality in the association between long-term orientation and language.

Table 10 reports the estimation results. In line with the findings by Chen (2013), the marginal effect of long-term orientation is positive and significant for individuals with a high proficiency of the language of their ancestors, but three times smaller and insignificant in the sample of individuals who do not speak the language of their ancestors. This evidence supports the hypothesis that long-term orientation might be induced by the act of speaking a language with weak future-time reference, and vice versa. Again, this is only true under the maintained assumption that the language structure reflects differences in long-term orientation across different nations.

\footnotetext{
${ }^{26}$ Only $8 \%$ of the sample have a mother tongue that has a strong future orientation.
} 
One competing explanation for our findings in Table 10 could however be that parents who pass on the language to their children may also be more likely to transmit other cultural values to their children, since they might in general be more attached to the culture of their home country. I.e. whether a second-generation migrant speaks the language of the country of ancestry is an endogenous outcome, and parents with strong cultural ties to their home country might be more likely to teach their children the language of the home country, but also to transmit the home country's culture in general. To test this alternative explanation, in Table 10 we repeat the exercise of splitting the sample according to the language proficiency of the secondgeneration migrants, but analyze the effects of the cultural proxies thrift and wealth accumulation this time. Running the regressions with thrift and wealth accumulation as dependent variables, the results do not point to self-section. The marginal effects are similar between both high- and low-proficiency language samples, and for wealth accumulation even larger in the sample of second-generation immigrants with low language proficiency. Thus, our findings give some suggestive evidence supporting the hypothesis by Chen (2013) that languages can be important drivers of the transmission of long-term orientation. We want to stress again, though, that the underlying assumption of our study is that there is variation in the structure of languages in line with variation in the long-term orientation of the respective country.

In a recent paper, Galor and Özak (2016) empirically analyze the origins of variation in long-term orientation across countries. They trace it back to pre-industrial agro-climatic characteristics that entailed differences in the return to agricultural investment. The authors show that these differences in the agricultural return, measured by the potential crop yield, have a persistent effect on the geographical distribution of time preferences. The crop yield in the home country of the parents still matters for the behavior of secondgeneration migrants related to long-term orientation. Their results are robust to the inclusion of the futuretime reference language-variables provided by Chen (2013). Still, their results indicate that the future-time reference of a language may in addition play an independent role in explaining long-term orientation. In Galor et al. (2016), the authors go one step further and show that pre-industrial geographic characteristics are at the root of variation of modern languages with respect to future-orientation, but also other language characteristics, and establish an independent role of languages for educational outcomes. In line with our evidence, they thus provide some evidence that the act of speaking a language matters for the transmission of long-term orientation. 


\section{External Validity: Evidence from the UK}

For Germany, we find robust evidence that attitudes towards thrift and wealth accumulation in the country of ancestry have an impact on the saving rates of second-generation immigrants, pointing to the importance of culture for saving decisions. Does this hold true in general? In this section, we address the external validity of our results by studying evidence from an alternative major European immigration country, namely the UK. Confirming results in a different data set may also help mitigating the risk of spurious results associated with multiple hypothesis testing (see Fafchamps and Labonne, 2016).

\subsection{Data}

We use data from the Understanding Society survey, a representative household panel survey that started in 2009. The saving question that we exploit is the following: "Do you save any amount of your income, for example by putting something away now and then in a bank, building society, or Post Office account, other than to meet regular bills? Please include share purchase schemes, ISAs and Tessa accounts. About how much on average do you personally manage to save a month?" This question is available in wave 2 (2010-2012) and wave 4 (2012-2014) of the survey and is asked at the individual level, which means that we conduct our analysis at the individual level rather than the household level as in Germany. We define the saving rate in the same way as before and divide the average monthly amount of savings by the average individual monthly net income. ${ }^{27}$

A major advantage of the Understanding Society data set is that we can directly observe the birth country of the parents and, thus, the identification of second-generation immigrants is straightforward. We include an individual in our sample if he or she was born in the UK and either the mother or the father was born abroad. If the mother was born in a foreign country, we assign the birth country of the mother as country of ancestry. In a second step, we assign the birth country of the father, if the mother was born in the UK and the father stems from a different country. The Understanding Society data set only allows distinguishing between 23 countries of origin, which means that the variation is much lower than in the GSOEP data set (69 countries). Table 11 reports the composition of the sample. Even though the majority of immigrants stems from European countries as in the GSOEP, the sample also contains many people from Asia, especially from India and Pakistan. Moreover, we observe second-generation immigrants from Africa, America, and also

\footnotetext{
${ }^{27}$ As for the GSOEP, we drop observations with saving rates greater than $100 \%$, therefore dropping mostly individuals with zero individual income but still positive savings.
} 
Table 11: Composition of the UK Sample

\begin{tabular}{lllll}
\hline Europe (2047) & Asia (1466) & Americas (787) & Africa (311) & Oceania (62) \\
\hline Cyprus (60) & Bangladesh (147) & Canada (118) & Ghana (45) & Australia (49) \\
France (62) & China/Hong Kong (66) & Jamaica (560) & Kenya (76) & New Zealand (13) \\
Germany (263) & India (697) & USA (109) & Nigeria (102) & \\
Italy (150) & Pakistan (507) & & South Africa (66) & \\
Poland (125) & Sri Lanka (37) & & Uganda (22) & \\
Rep. of Ireland (1345) & Turkey (12) & & & \\
Spain (42) & & & \\
\hline
\end{tabular}

The number of observations is indicated in brackets. If countries belong to more than one continent, the country is classified according to largest geographical area.

from Australia and New Zealand. Within Europe, the largest immigrant group comes from the Republic of Ireland, followed by Germany. Overall, the distribution of countries of ancestry is thus quite different from the distribution in the German sample. Thus, the UK sample provides a lot of independent variation in the cultural traits from the German sample.

We apply the same sample selection criteria as before and only consider second-generation immigrants that are between 25 and 65 years old. We also define the control variables in a way to make them as consistent as possible with the GSOEP data. Our final sample consists of 4,673 observations.

\subsection{Results}

We estimate the same Tobit model as before and account for the clustering of the standard errors at the country of origin level. The regressions control for individual characteristics, time fixed effects, and regional fixed effects, which are defined at the NUTS 1 level for the UK. ${ }^{28}$ Table 12 reports the results. Both the marginal effects of thrift and wealth accumulation are positive and significantly different from zero, consistent with our previous results. For thrift, we find that a one standard deviation increase in thrift (13.70) is associated with an increase of the saving rate of 0.41 percentage points. Increasing the wealth accumulation motive by one standard deviation (16.29) leads to an increase of the saving rate by 0.33 percentage points. While the estimated effects are thus smaller than the ones in the German sample, the results confirm our finding that these two cultural channels matter for the saving behavior of households.

\footnotetext{
${ }^{28}$ Appendix Figure A4 shows the raw correlations between saving rates of second-generation migrants and the cultural variables in scatterplots. As for Germany, the figure only includes countries with more than 15 observations.
} 
Table 12: UK Results

\begin{tabular}{|c|c|c|c|c|c|c|}
\hline Cultural variables & $\begin{array}{l}(1) \\
\text { Thrift }\end{array}$ & $\begin{array}{c}(2) \\
\text { Wealth } \\
\text { accumulation }\end{array}$ & $\begin{array}{c}(3) \\
\text { Indulgence }\end{array}$ & $\begin{array}{c}(4) \\
\text { Indulgence }\end{array}$ & $\begin{array}{c}\text { (5) } \\
\text { Long-term } \\
\text { orientation }\end{array}$ & $\begin{array}{c}\text { (6) } \\
\text { Uncertainty } \\
\text { avoidance }\end{array}$ \\
\hline Source & WVS / EVS & SVS & SVS & Hofstede & Hofstede & Hofstede \\
\hline $\begin{array}{l}\text { Marginal effect of } \\
\text { cultural variable }\end{array}$ & $\begin{array}{l}0.04 * * \\
(0.02)\end{array}$ & $\begin{array}{l}0.02 * \\
(0.01)\end{array}$ & $\begin{array}{l}-0.02 * \\
(0.01)\end{array}$ & $\begin{array}{c}-0.02 * * \\
(0.01)\end{array}$ & $\begin{array}{c}0.01 \\
(0.01)\end{array}$ & $\begin{array}{c}0.00 \\
(0.01)\end{array}$ \\
\hline Observations & 4000 & 3346 & 2589 & 3978 & 3918 & 4265 \\
\hline No. of countries & 20 & 18 & 16 & 19 & 18 & 16 \\
\hline Individual controls & YES & YES & YES & YES & YES & YES \\
\hline Regional FE (NUTS1) & YES & YES & YES & YES & YES & YES \\
\hline Time FE & YES & YES & YES & YES & YES & YES \\
\hline
\end{tabular}

Significance levels: $* * * \mathrm{p}<0.01, * * \mathrm{p}<0.05, * \mathrm{p}<0.1$. The dependent variable is the individual saving rate. We estimate a Tobit model. Clustered standard errors (at country of origin level) are reported in parentheses. Individual controls are: age group dummies for 5 ages, income decile dummies, permanent income decile dummies, gender dummy, labor market status: dummies for unemployed, not in labor force, retired, self employed, civil servant, marital status: dummies for married, divorced, widowed, five education dummies, 3 kids dummies: 1 kid, 2 kids, 3 or more kids, and a numerical control variable for the number of adults in the household.

As for Germany, we do not find any evidence of a positive cultural effects of the long-term orientation and uncertainty avoidance motives on individual saving decisions in UK. Contrary to the German case, however, in the UK sample we do find that both indulgence measures from the country of ancestry are negative and significantly related to the saving choices of second-generation immigrants. This leaves the importance of indulgence as a cultural trait for saving behavior as somewhat of an open question for future research.

\section{Conclusion}

In this paper, we analyze whether culture matters for the saving behavior of private households by correlating the saving behavior of second-generation immigrants in Germany and the UK to cultural attitudes in the country of their ancestors that should matter for savings decisions. We conclude that culture has a significant effect on the saving behavior of households. The two main cultural aspects for which we robustly identify a significant relationship to the saving behavior of second-generation migrants are attitudes towards thrift and the importance assigned to wealth accumulation. We do not find significant effects of the other cultural channels considered here, namely indulgence and attitudes towards uncertainty. Since these attitudes from the home country also do not matter for the saving behavior of first-generation migrants, we conclude 
that either we do measure them with too much error, or they are in general no significant determinants of saving behavior on the national level. While long-term orientation in the country of ancestry is not robustly associated with the saving behavior of second-generation migrants, we report evidence that is is associated with their behavior for the subsample of second-generation migrants who speak the language of their country of ancestry well. This is in line with the findings by Chen (2013) and Sutter et al. (2015) that speaking a language with either strong or weak future-reference in its structure has an impact on the long-term orientation of individuals.

We base our choice of cultural variables on a list of psychological factors proposed by Wärneryd (1999). It is important to mention that neither he nor we make the claim to be exhaustive. There may potentially be other cultural dimensions that go beyond the ones that we study and that may have an impact on the saving decisions of households. One possible candidate could be the importance of family ties. Alesina and Giuliano (2010) demonstrate that differences in family ties help explain a variety of household choices. However, the direction of the effect of stronger family ties on savings is not obvious a priori. Stronger family ties could lead to more saving, e.g. to leave a bequest for the children or take care of parents during old age, or less saving, e.g. because of expectations of receiving a bequest from parents or because of increased withinfamily insurance. It remains an open task for future research to investigate additional cultural channels on saving behavior. 


\section{References}

Alesina, A. and P. Giuliano (2010). The Power of the Family. Journal of Economic Growth 15(2), 93-125.

Bauer, T. K. and M. G. Sinning (2011). The Savings Behavior of Temporary and Permanent Migrants in Germany. Journal of Population Economics 24(2), 421-449.

Blau, F. D. (2015). Immigrants and Gender Roles: Assimilation vs. Culture. IZA Journal of Migration 4(1), $1-21$.

Carroll, C. D., B.-K. Rhee, and C. Rhee (1994). Are there Cultural Effects on Saving? Some Cross-Sectional Evidence. The Quarterly Journal of Economics, 685-699.

Carroll, C. D., B.-K. Rhee, and C. Rhee (1999). Does Cultural Origin Affect Saving Behavior? Evidence from Immigrants. Economic Development and Cultural Change 48(1), 33-50.

Chen, M. K. (2013). The Effect of Language on Economic Behavior: Evidence from Savings Rates, Health Behaviors, and Retirement Assets. American Economic Review 103(2), 690-731.

Cronqvist, H. and S. Siegel (2015, February). The Origins of Saving Behavior. Journal of Political Economy 123(1), 123-169.

Díez-Medrano, J. (2009). Building a Five Wave WVS-EVS Aggregate File from Existing Official Files Available on the Web. www.worldvaluessurvey.org.

DIW Berlin / SOEP (2014). SOEP 2013 - Documentation of the person-related meta-dataset PPFAD for SOEP v30. SOEP Survey Papers 251.

Dustmann, C. and J. Mestres (2010). "remittances and temporary migration". Journal of Development Economics 92(1), 62-70.

EVS (2011). European Values Study 1981-2008, Longitudinal Data File. GESIS Data Archive, Cologne, Germany, ZA4804 Data File Version 2.0.0 (2011-12-30).

Fafchamps, M. and J. Labonne (2016). Using Split Samples to Improve Inference about Causal Effects. National Bureau of Economic Research 21842.

Fernández, R. (2007). Alfred Marshall Lecture Women, Work, and Culture. Journal of the European Economic Association 5(2-3), 305-332.

Fernández, R. (2008). Culture and Economics. In S. N. Durlauf and L. E. Blume (Eds.), The New Palgrave Dictionary of Economics. Basingstoke: Palgrave Macmillan.

Fernández, R. and A. Fogli (2009). Culture: An Empirical Investigation of Beliefs, Work, and Fertility. American Economic Journal: Macroeconomics 1(1), 146-177. 
Figlio, D. N., P. Giuliano, U. Özek, and P. Sapienza (2016, August). Long-term orientation and educational performance. Technical Report w22541, National Bureau of Economic Research.

Furtado, D., M. Marcén, and A. Sevilla (2013). Does Culture Affect Divorce? Evidence from European Immigrants in the United States. Demography 50(3), 1013-1038.

Galor, O. and O. Özak (2016). The Agricultural Origins of Time Preference. American Economic Review, forthcoming.

Galor, O., O. Özak, and A. Sarid (2016). Geographical Origins and Economic Consequences of Language Structures. IZA Discussion Paper 10379.

Giuliano, P. (2007). Living Arrangements in Western Europe: Does Cultural Origin Matter? Journal of the European Economic Association 5(5), 927-952.

Guin, B. (2015). Culture and Household Saving. University of St. Gallen.

Guiso, L., P. Sapienza, and L. Zingales (2004). The Role of Social Capital in Financial Development. American Economic Review 94(3), 526-556.

Guiso, L., P. Sapienza, and L. Zingales (2006). Does Culture Affect Economic Outcomes? The Journal of Economic Perspectives 20(2), 23-48.

Haliassos, M., T. Jansson, and Y. Karabulut (2015). Incompatible European Partners? Cultural Predispositions and Household Financial Behavior. Sveriges Riksbank (Central Bank of Sweden).

Hofstede, G. (1980). Culture's Consequences: International Differences in Work-Related Values. Beverly Hills CA: Sage Publications.

Hofstede, G. (2011). Dimensionalizing Cultures: The Hofstede Model in Context. Online Readings in Psychology and Culture 2(1), 8.

Hofstede, G., G. Hofstede, and M. Minkov (2010). Cultures and Organizations: Software of the Mind, Third Edition. McGraw-Hill Education.

Hofstede, G. and G. J. Hofstede (2005). Cultures and Organizations: Software of the Mind. (2nd ed.). New York: McGraw-Hill USA.

Huber, S. J. and T. Schmidt (2016). Cross-Country Differences in Homeownership: A Cultural Phenomenon? Mimeo.

Knowles, J. and A. Postlewaite (2004). Do Children Learn to Save from Their Parents? Unpublished Manuscript, University of Pennsylvania.

Luttmer, E. F. and M. Singhal (2011). Culture, context, and the taste for redistribution. American Economic Journal. Economic Policy 3(1), 157. 
Marshall, A. (1920). Principles of Economics: an Introductory Volume. Macmillan London. (First published in 1890).

Moriconi, S. and G. Peri (2015). Country-Specific Preferences and Employment Rates in Europe. National Bureau of Economic Research 21561.

Osili, U. O. and A. L. Paulson (2008). Institutions and Financial Development: Evidence from International Migrants in the United States. The Review of Economics and Statistics 90(3), 498-517.

Paule, H. (2012). Determinants of Saving Rates: Does Culture Matter? Master's thesis, Goethe University Frankfurt.

Scheller, F. (2011). Bestimmung der Herkunftsnationen von Teilnehmern des Soziooekonomischen Panels (SOEP) mit Migrationshintergrund. SOEPpapers on Multidisciplinary Panel Data Research 407.

Schwartz, S. H. (1999). A Theory of Cultural Values and Some Implications for Work. Applied Psychology $48(1), 23-47$.

Schwartz, S. H. (2005). Basic Human Values: Their Content and Structure across Countries. In A. Tamayo and J. B. Porto (Eds.), Valores e Comportamento nas Organizações [Values and Behavior in Organizations], pp. 21-55. Petrópolis, Brazil: Vozes.

Schwartz, S. H. (2012). An Overview of the Schwartz Theory of Basic Values. Online Readings in Psychology and Culture 2(1), 11.

Sinning, M. G. (2011). Determinants of Savings and Remittances: Empirical Evidence from Immigrants to Germany. Review of Economics of the Household 9(1), 45-67.

Sutter, M., S. Angerer, D. Glätzle-Rützler, and P. Lergetporer (2015). The Effect of Language on Economic Behavior: Experimental Evidence from Children's Intertemporal Choices. IZA Discussion Papers.

Wagner, G. G., J. Göbel, P. Krause, R. Pischner, and I. Sieber (2008). Das Sozio-oekonomische Panel (SOEP): Multidisziplinäres Haushaltspanel und Kohortenstudie für Deutschland-Eine Einführung (für neue Datennutzer) mit einem Ausblick (für erfahrene Anwender). AStA Wirtschafts-und Sozialstatistisches Archiv 2(4), 301-328.

Wärneryd, K. E. (1999). The Psychology of Saving: A Study on Economic Psychology. Edward Elgar Publishing.

WVS (2009). World Values Survey 1981-2008 official aggregate v.20090901. World Values Survey Association (www.worldvaluessurvey.org). Aggregate File Producer: ASEP/JDS, Madrid. 


\section{A Online appendix}

\section{A.1 Identification of Second-Generation Migrants in the GSOEP}

Usually, second-generation migrants are identified as individuals being born in the host country, but whose parents migrated from some home country to the host country. This rather straight-forward identification is not possible in the GSOEP. However, the variable "migback" indicates whether an individual has an indirect migration background. Indirect migrants are defined as individuals who are born in Germany and have either at least one parent who is non-German or was born outside of Germany, or have or had themselves a non-German citizenship. Thus, they contain second-generation migrants under the standard definition, but in addition also other individuals. For example, as the GSOEP documentation points out, also "an individual who gains a foreign nationality will be classified as being of migrant origin" (DIW Berlin / SOEP, 2014).

In order to identify the country of origin of the indirect migrants, we largely follow the procedure proposed by Scheller (2011). We conduct the following steps:

1. In a first step we gather information on non-German nationalities that were stated by the individual in different waves. If the individual named different nationalities in different waves, the nationality that was mentioned most often is assigned. If one nationality was mentioned as often as another one, we keep the last-mentioned nationality.

2. If the variables in the first step are uninformative, we consider information provided by the interviewer on the nationalities of respondents. This information is especially useful for household members who were not interviewed themselves (e.g. kids), and is thus of minor importance for us, as we focus on household heads. If nationalities named by the interviewer differ among waves, we proceed as in step one.

3. For indirect migrants where the country of origin is still unclear, we exploit a retrospective variable on past citizenships in a third step.

4. In step four we use information provided by the household head on the citizenships of children that were living in the household (the variable is available in two waves).

5. Since 2000, information on a second citizenship was collected. We make use of this variable in the fifth step.

6. In a sixth step we cross-check the countries of birth mentioned in different waves to see whether they deviate from the main country of birth variable "corigin", which names Germany for all indirect migrants. We find several deviations (especially for people from Poland and the Czech Republic). If a foreign country of birth was mentioned in at least one wave, we attach this nationality to the individual.

7. Finally, if we cannot identify a foreign nationality in the first six steps, we link individuals to their parents if they also participate in the survey and consider parental information. To identify the nationality of the parents, we follow the same procedure as described in steps 1 to 6 . Only in recent 
years (since 2012) individuals were asked for the country of origin of their parents directly. We use this information either if steps 1 to 6 did not provide the country of origin of the parents or if the parents are not part of the survey. If the father and the mother stem from different countries, we assign the maternal nationality to the individual. If the mother is German and the father has a non-German nationality, the father's home country is assigned.

\section{A.2 Construction of the Hofstede Variables}

\section{Long-Term Orientation}

The dimension long-term orientation is defined as follows: "long-term orientation stands for the fostering of virtues oriented toward future rewards - in particular, perseverance and thrift. Its opposite pole, shortterm orientation, stands for the fostering of virtues related to the past and present - in particular, respect for tradition, preservation of "face" and fulfilling social obligations." (Hofstede et al., 2010)

Hofstede et al. (2010) construct the scores of the dimension based on a factor analysis of three variables from the World Value Survey (WVS), namely, thrift, national pride and importance of service to others. The survey question for thrift is "Here is a list of qualities that children can be encouraged to learn at home. Which, if any, do you consider to be especially important? Please choose up to five." One of the items on the list is "thrift (saving money and things)" and Hofstede et al. (2010) compute the percentage for each country that name this item. The question for national pride is "How proud are you to be (name of your nationality)? Very proud, quite proud, not very proud, not at all proud." Hofstede et al. (2010) use the percentage of respondents choosing "very proud". To measure the importance of service to others, the WVS question is: "For each of the following, indicate how important it is in your life - very important, rather important, not very important or not at all important." Among the items on the list is "service to others" and Hofstede et al. (2010) compute the percentage that indicate that service to others is "very important".

The factor analysis of these three variables results in a single factor that accounts for 70 percent of the variance in the variables and the following loadings: importance of service to others: 0.94, national pride: 0.86, thrift: -0.7 (Hofstede et al., 2010). Some missing scores of importance of service to others are imputed based on the other two variables, the sign of the scores is reversed and the variable is converted to a scale from 0 to 100 .

\section{Uncertainty Avoidance}

Uncertainty avoidance is defined as "the extent to which the members of a culture feel threatened by ambiguous or unknown situations." (Hofstede et al., 2010)

The dimension is part of the four original dimensions that Hofstede discovered based on interviews of IBM employees. The dimension is based of the variables job stress, rule orientation and plan of a long-term career at IBM. As a measure of job stress, Hofstede et al. (2010) compute the mean answer to the question "How often do you feel nervous or tense at work" on a scale from "(1) I always feel this way" to "(5) I never feel this way". To measure rule orientation, Hofstede et al. (2010) use the mean answer to the statement "Company rules should not be broken - even when the employee thinks it is in the company's best interest" 
(scale from 1 to 5). Finally, the percentage of employees that strive for a long-term career at the company is measured based on the question "How long do you think you will continue working for IBM - (1) Two years at most, (2) From two to five years, (3) More than five years (but I will probably leave before I retire), and (4) Until I retire.” Hofstede et al. (2010) compute the percentage that choose answer 3 or 4.

They construct an index by "adding or subtracting the three scores after multiplying each by a fixed number, and finally adding another fixed number" in a way such that all three variables have the same contribution to the index and the values vary on a scale from 0 to 100 . While there are still some country values slightly above 100 in Hofstede et al. (2010), we use the adjusted scores that only range between 0 and 100 and which are available here: http://www.geerthofstede.com/dimension-data-matrix.

\section{Indulgence versus Restraint}

According to Hofstede et al. (2010) the definition of indulgence versus restraint is: "Indulgence stands for a tendency to allow relatively free gratification of basic and natural human desires related to enjoying life and having fun. Its opposite pole, restraint, reflects a conviction that such gratification needs to be curbed and regulated by strict social norms."

The dimension is based on the three variables happiness, life control and importance of leisure taken from the WVS. The question on happiness is: "Taking all things together, would you say you're very happy, quite happy, not very happy or not happy at all.” Hofstede et al. (2010) compute the percentage answering "very happy". To measure life control, the average score of the following question is used: "Some people feel they have completely free choice over their lives, while other people feel that what they do has no real effect on what happens to them. Please use this scale where 1 means 'none at all' and 10 means 'a great deal' to indicate how much freedom of choice and control you feel you have over the way your life turns out." The third variable, importance of leisure, is based on the question: "For each of the following, indicate how important it is in your life: very important, rather important, not very important, or not at all important." One of the items on the list is leisure time and Hofstede et al. (2010) compute the percentage of respondents answering "very important".

Hofstede et al. (2010) use the average of the three variables over time and factor-analyze them, which leads to a single factor. The loadings are as follows: happiness: 0.87 , average life control: 0.84 , importance of leisure: 0.84 . The scores are re-scaled to range between 0 and 100 . 


\section{A.3 Country Saving Rates}

Figure A1: Saving Rates of Second-Generation Immigrants and Aggregate Saving Rates in Home Country

(a) National saving rate (WB)

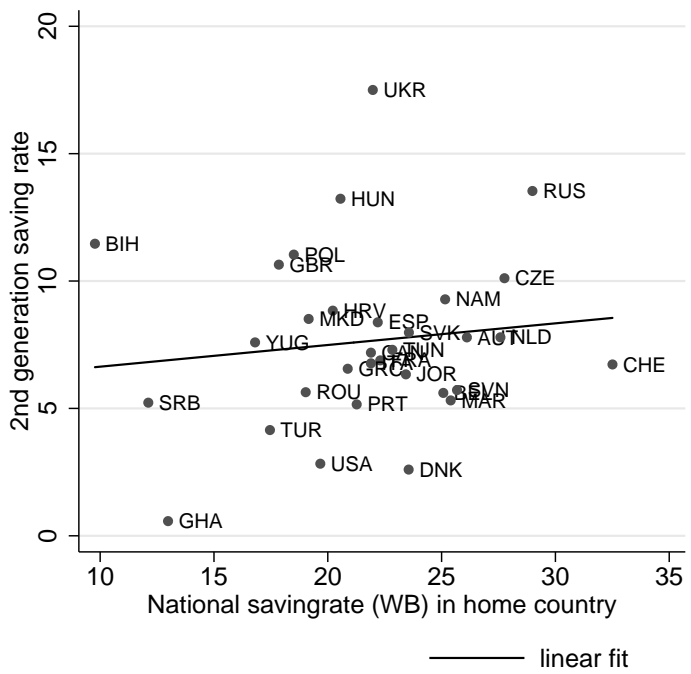

(c) National saving rate (WB)

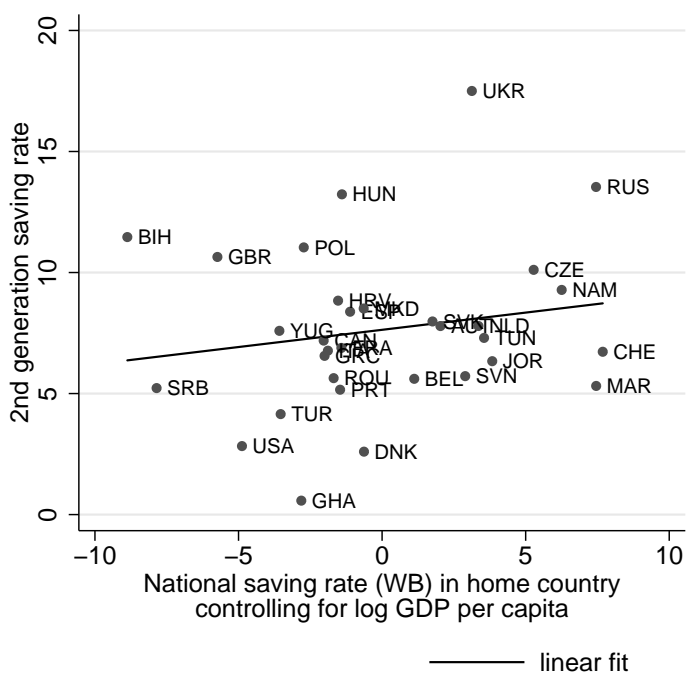

(b) Household saving rate (OECD)

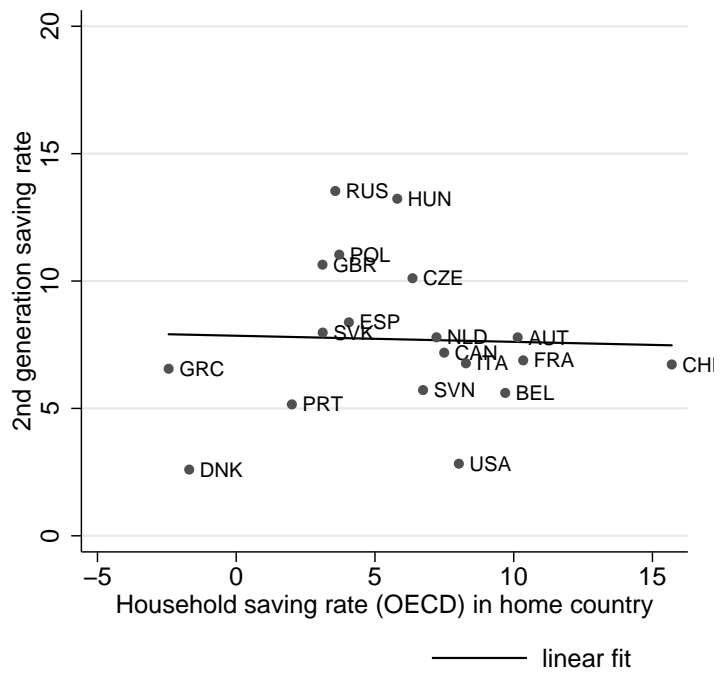

(d) Household saving rate (OECD)

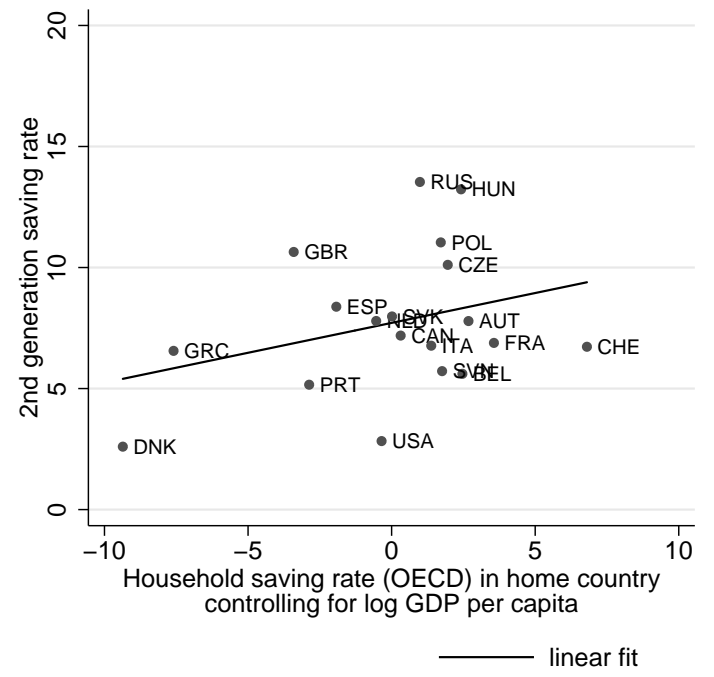


Figure A2: Evolution of National Saving Rate (WB)

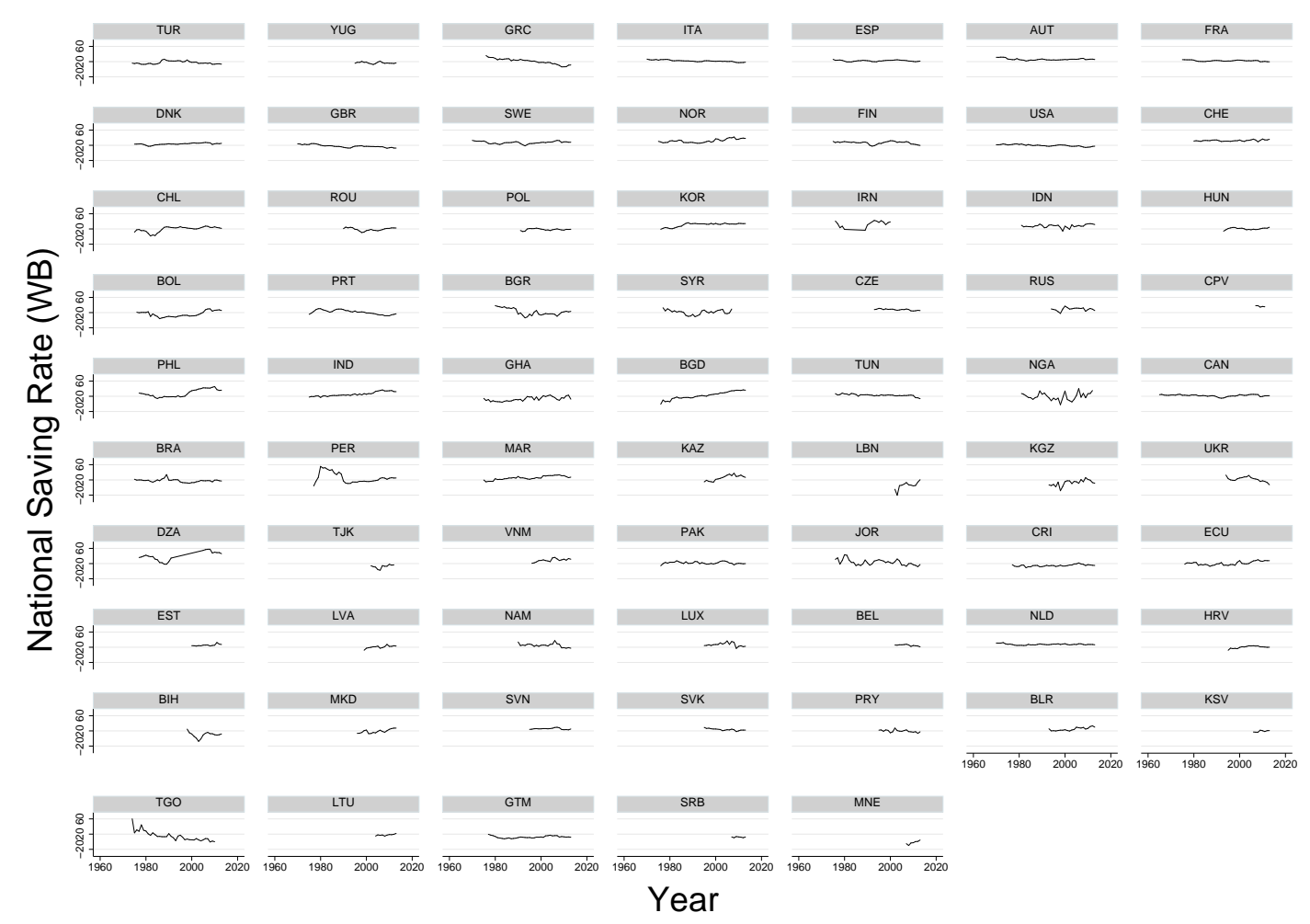


Figure A3: Evolution of Household Saving Rate (OECD)

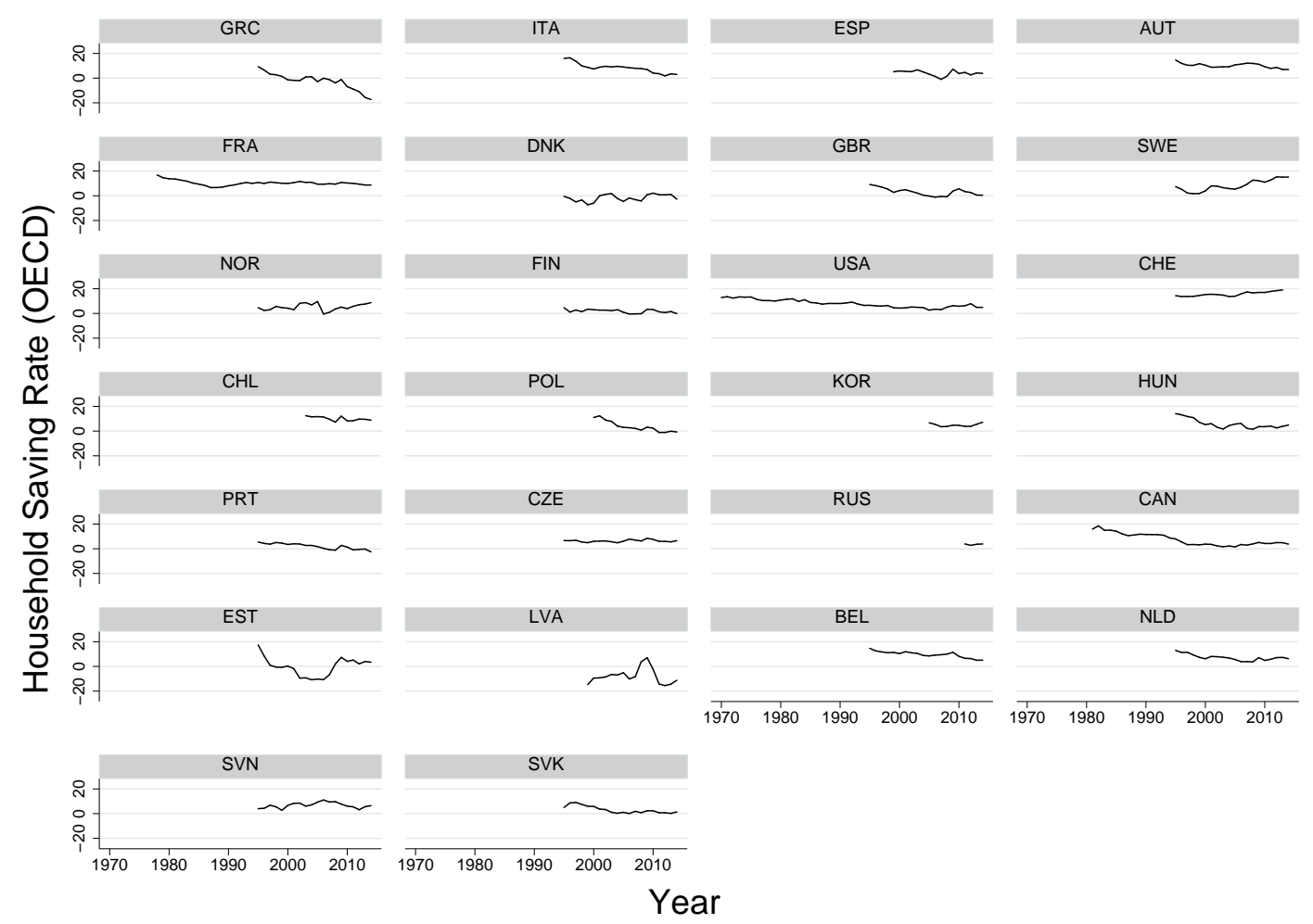




\section{A.4 UK Graphs}

Figure A4: Saving Rates of Second-Generation Immigrants in the UK and Cultural Values in Home Country

(a) Thrift

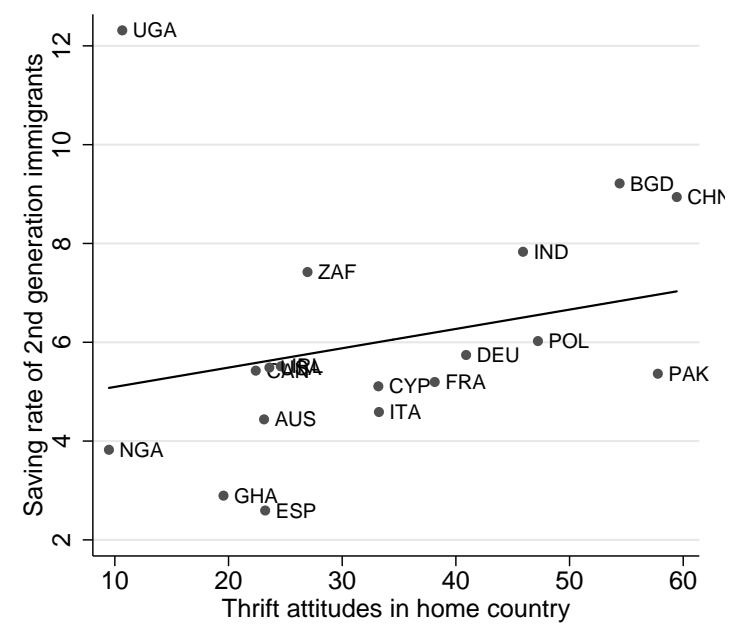

linear fit

(c) Indulgence (SVS)

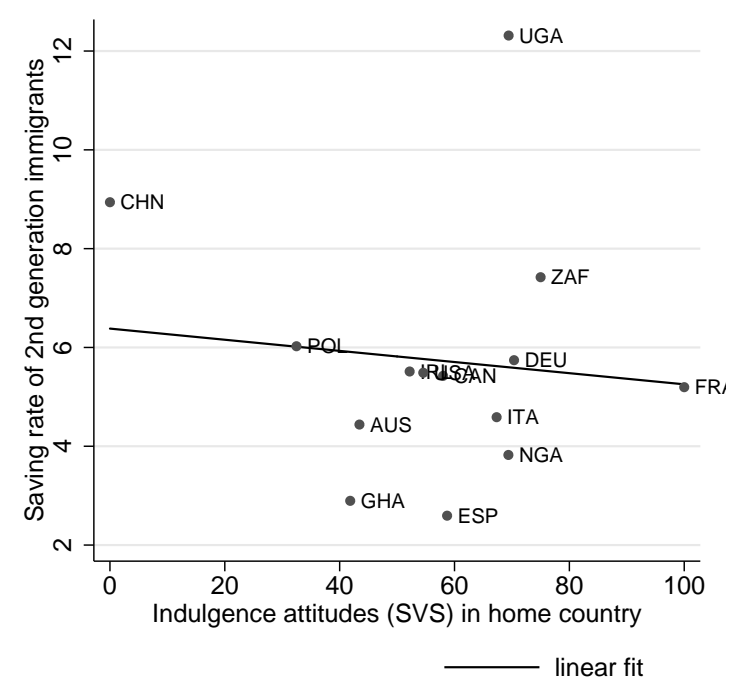

(e) Long-Term Orientation

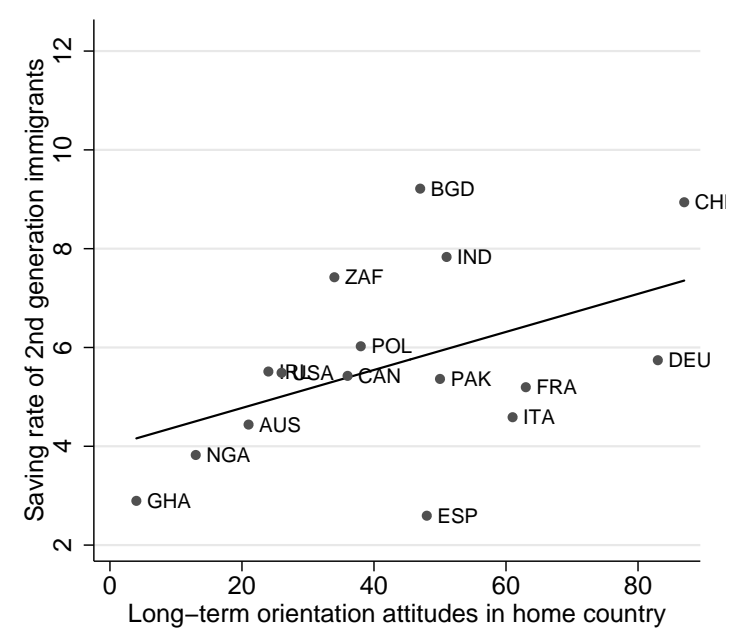

linear fit (b) Wealth Accumulation

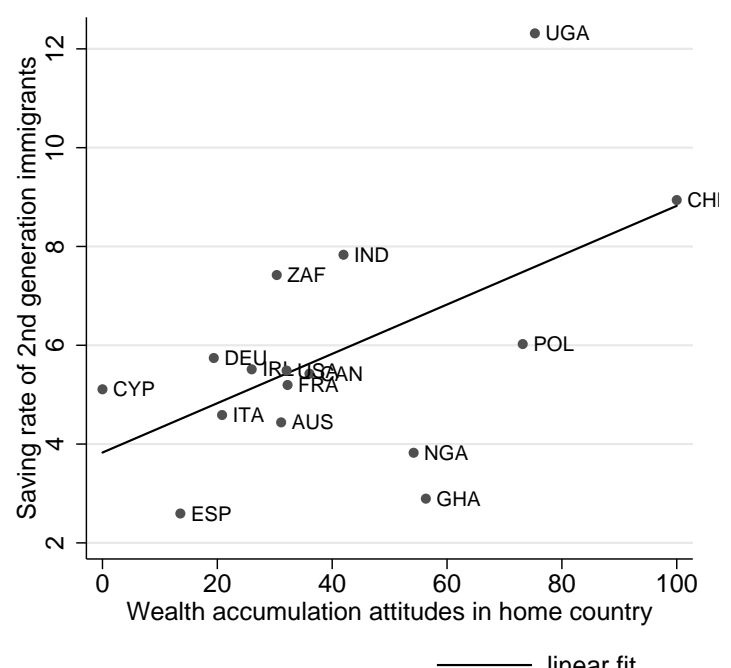

(d) Indulgence (Hofstede)

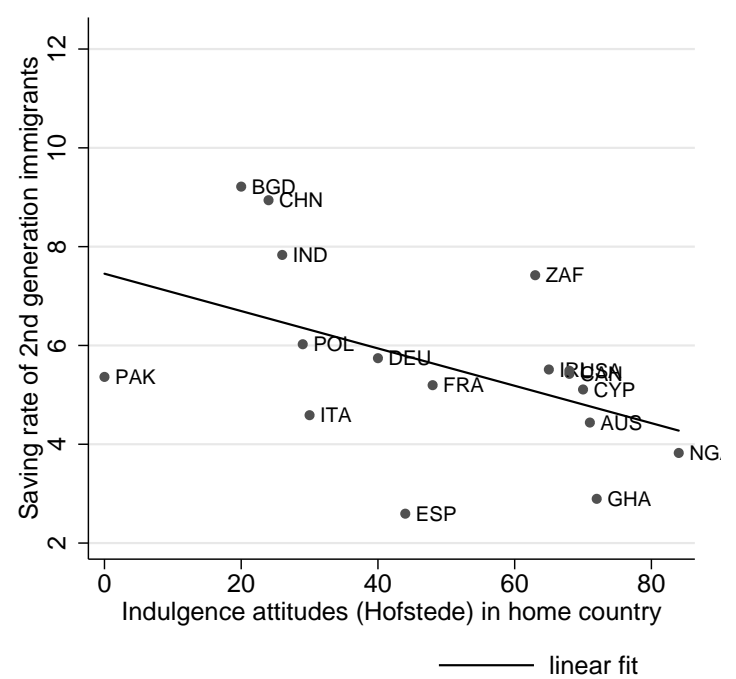

(f) Uncertainty Avoidance

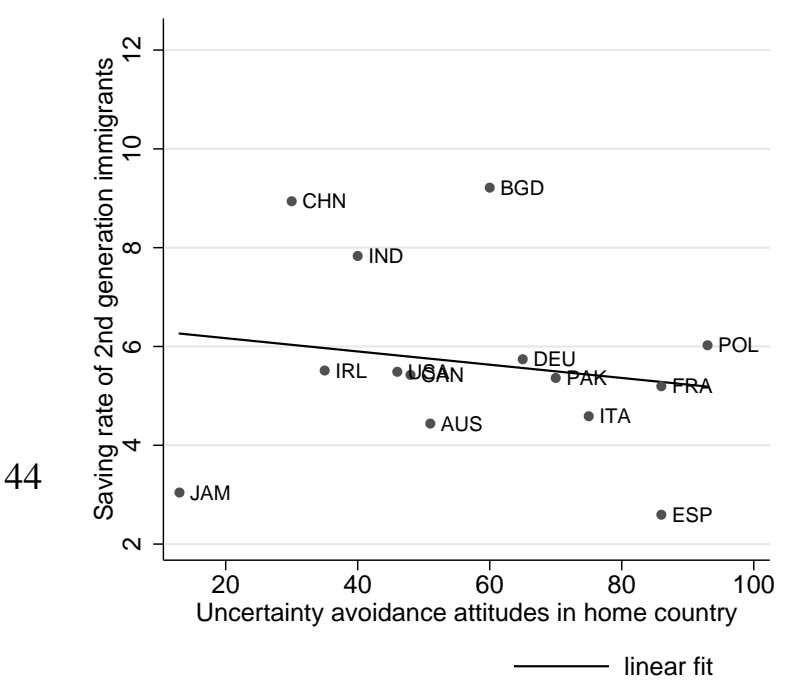




\section{A.5 Additional Results for Parents and Children}

Table A1: Results for Temporary and Permanent Parents and Their Children

Panel A: parents

(1)

Cultural variables Thrift

Source

Marginal effect of

cultural variable

$(0.05)$

Observations

Individual controls

State dummies

Year FE

Panel B: children

\begin{tabular}{lcccccc}
\hline Cultural variables & $\begin{array}{c}(1) \\
\text { Thrift }\end{array}$ & $\begin{array}{c}(2) \\
\text { Wealth } \\
\text { accumulation } \\
\text { Source }\end{array}$ & $\begin{array}{c}(3) \\
\text { Indulgence }\end{array}$ & $\begin{array}{c}(4) \\
\text { Indulgence }\end{array}$ & $\begin{array}{c}(5) \\
\text { Long-term } \\
\text { orientation } \\
\text { Hofstede }\end{array}$ & $\begin{array}{c}\text { Uncertainty } \\
\text { avoidance } \\
\text { Hofstede }\end{array}$ \\
\hline $\begin{array}{l}\text { Marginal effect of } \\
\text { cultural variable }\end{array}$ & $0.09 * *$ & $0.04^{*}$ & -0.02 & -0.03 & 0.03 & -0.01 \\
& $(0.04)$ & $(0.02)$ & $(0.03)$ & $(0.03)$ & $(0.03)$ & $(0.03)$ \\
Observations & 3233 & 3237 & 3147 & 2802 & 2802 & 2754 \\
$\begin{array}{l}\text { Individual controls } \\
\text { State dummies }\end{array}$ & YES & YES & YES & YES & YES & YES \\
Year FE & YES & YES & YES & YES & YES & YES \\
\hline
\end{tabular}

Significance levels: $* * * \mathrm{p}<0.01, * * \mathrm{p}<0.05, * \mathrm{p}<0.1$. The dependent variable is the household saving rate. We estimate a Tobit model. Clustered standard errors (at country of origin level) are reported in parentheses. Individual controls are: age-group dummies for 5 ages, income decile dummies, permanent income decile dummies, gender dummy, labor market status: dummies for unemployed, not in labor force, retired, self employed, civil servant, marital status: dummies for married, divorced, widowed, five education dummies (ISCED categories), 3 kids dummies: 1 kid, 2 kids, 3 or more kids and a numerical control variable for the number of adults in the household. We do not impose any age restriction here. The sample of parents is not restricted to either temporary or permanent immigrants. 
Table A2: Results for Temporary and Permanent Parents and Their Children including Remittances

Panel A: parents

(1)

(3)

(4)

(5)

Cultural variables Thrift

Wealth

Indulgence Indulgence

Long-term

Uncertainty accumulation

orientation avoidance

Source

WVS / EVS

SVS

SVS

Hofstede

Hofstede

Hofstede

\begin{tabular}{lcccccc} 
Marginal effect of & 0.10 & 0.06 & 0.03 & 0.00 & 0.05 & 0.00 \\
cultural variable & $(0.06)$ & $(0.04)$ & $(0.03)$ & $(0.03)$ & $(0.04)$ & $(0.02)$ \\
& & & & & & \\
Observations & 3200 & 3176 & 3093 & 2653 & 2653 & 2660 \\
Individual controls & YES & YES & YES & YES & YES & YES \\
State dummies & YES & YES & YES & YES & YES & YES \\
Year FE & YES & YES & YES & YES & YES & YES \\
\hline
\end{tabular}

Panel B: children

\begin{tabular}{|c|c|c|c|c|c|c|}
\hline $\begin{array}{l}\text { Cultural variables } \\
\text { Source }\end{array}$ & $\begin{array}{c}\text { (1) } \\
\text { Thrift } \\
\text { WVS / EVS }\end{array}$ & $\begin{array}{c}(2) \\
\text { Wealth } \\
\text { accumulation } \\
\text { SVS }\end{array}$ & $\begin{array}{c}\text { (3) } \\
\text { Indulgence } \\
\text { SVS }\end{array}$ & $\begin{array}{l}\text { (4) } \\
\text { Indulgence } \\
\text { Hofstede }\end{array}$ & $\begin{array}{l}\quad(5) \\
\text { Long-term } \\
\text { orientation } \\
\text { Hofstede }\end{array}$ & $\begin{array}{c}\text { (6) } \\
\text { Uncertainty } \\
\text { avoidance } \\
\text { Hofstede }\end{array}$ \\
\hline $\begin{array}{l}\text { Marginal effect of } \\
\text { cultural variable }\end{array}$ & $\begin{array}{l}0.08 * \\
(0.04)\end{array}$ & $\begin{array}{c}0.03 \\
(0.03)\end{array}$ & $\begin{array}{l}-0.03 \\
(0.03)\end{array}$ & $\begin{array}{l}-0.01 \\
(0.04)\end{array}$ & $\begin{array}{c}0.02 \\
(0.04)\end{array}$ & $\begin{array}{c}0.00 \\
(0.04)\end{array}$ \\
\hline Observations & 2534 & 2538 & 2468 & 2198 & 2198 & 2156 \\
\hline Individual controls & YES & YES & YES & YES & YES & YES \\
\hline State dummies & YES & YES & YES & YES & YES & YES \\
\hline Year FE & YES & YES & YES & YES & YES & YES \\
\hline
\end{tabular}

Significance levels: $* * * \mathrm{p}<0.01, * * \mathrm{p}<0.05, * \mathrm{p}<0.1$. The dependent variable is the household saving rate including remittances. We estimate a Tobit model. Clustered standard errors (at country of origin level) are reported in parentheses. Individual controls are: age-group dummies for 5 ages, income decile dummies, permanent income decile dummies, gender dummy, labor market status: dummies for unemployed, not in labor force, retired, self employed, civil servant, marital status: dummies for married, divorced, widowed, five education dummies (ISCED categories), 3 kids dummies: 1 kid, 2 kids, 3 or more kids and a numerical control variable for the number of adults in the household. We do not impose any age restriction here. The sample of parents is not restricted to either temporary or permanent immigrants. 
Table A3: Results for Permanent Parents and Their Children including Remittances

Panel A: parents

(1)

Cultural variables Thrift

Cultural variables Thrift

Source

Marginal effect of

cultural variable

WVS / EVS

$(0.05)$
(3)

(2)

Wealth accumulation
(4)

Indulgence Indulgence

SVS

$0.10 * * *$

(0.03)

0.00

(0.03)

0.00

$0.07 *$

$-0.04$

1922

1873

(0.03)

(0.04)

(0.03)

Observations

1952

Individual controls

YES

YES

YES

1572

1572

1572

State dummies

YES

YES

YES

YES

YES

YES

Year FE

YES

YES

YES

YES

YES

YES

YES

YES

YES

Panel B: children

\begin{tabular}{|c|c|c|c|c|c|c|}
\hline Cultural variables & $\begin{array}{l}(1) \\
\text { Thrift }\end{array}$ & $\begin{array}{c}(2) \\
\text { Wealth } \\
\text { accumulation } \\
\text { SVS }\end{array}$ & $\begin{array}{c}\text { (3) } \\
\text { Indulgence } \\
\text { SVS }\end{array}$ & $\begin{array}{c}\text { (4) } \\
\text { Indulgence } \\
\text { Hofstede }\end{array}$ & $\begin{array}{l}\qquad(5) \\
\text { Long-term } \\
\text { orientation } \\
\text { Hofstede }\end{array}$ & $\begin{array}{c}\text { (6) } \\
\text { Uncertainty } \\
\text { avoidance } \\
\text { Hofstede }\end{array}$ \\
\hline $\begin{array}{l}\text { Marginal effect of } \\
\text { cultural variable }\end{array}$ & $\begin{array}{c}0.07 \\
(0.05)\end{array}$ & $\begin{array}{c}0.03 \\
(0.03)\end{array}$ & $\begin{array}{l}-0.04 \\
(0.03)\end{array}$ & $\begin{array}{c}0.00 \\
(0.04)\end{array}$ & $\begin{array}{c}0.02 \\
(0.05)\end{array}$ & $\begin{array}{l}-0.02 \\
(0.04)\end{array}$ \\
\hline Observations & 2222 & 2216 & 2146 & 1886 & 1886 & 1834 \\
\hline Individual controls & YES & YES & YES & YES & YES & YES \\
\hline State dummies & YES & YES & YES & YES & YES & YES \\
\hline Year FE & YES & YES & YES & YES & YES & YES \\
\hline
\end{tabular}

Significance levels: $* * * \mathrm{p}<0.01, * * \mathrm{p}<0.05, * \mathrm{p}<0.1$. The dependent variable is the household saving rate including remittances. We estimate a Tobit model. Clustered standard errors (at country of origin level) are reported in parentheses. Individual controls are: age-group dummies for 5 ages, income decile dummies, permanent income decile dummies, gender dummy, labor market status: dummies for unemployed, not in labor force, retired, self employed, civil servant, marital status: dummies for married, divorced, widowed, five education dummies (ISCED categories), 3 kids dummies: 1 kid, 2 kids, 3 or more kids and a numerical control variable for the number of adults in the household. We do not impose any age restriction here. The sample of parents consists of parents that self-report that they live in Germany permanently. 